\title{
Observations on the Biology and Cytology of Pythium ultimum, $n$. sp.
}

\author{
BY
}

A. H. TROW, D.Sc., F.L.S.

\section{With Plates XV and XVI.}

OR some years a detailed knowledge of the cytology
of the genus Pythium has been a great desideratum. Notwithstanding the attention which has been bestowed on the Phycomycetes, and especially on the Oomycetes in recent years, and the great interest which has been excited by the results achieved, this very interesting genus has been practically neglected. We need only to refer to the work of Wager ('89, '96, and '00) on Peronospora and Cystopus; Berlese ('97) on the same and other genera; Stevens ('99) and Davis ('00) on Albugo (Cystopus); Istvanffi ('95) on Cystopus, Saprolegnia, and other genera ; Humphrey ('92), Hartog ('95), Dangeard ('90), and myself ('95, '99) on Saprolegniaceae (chiefly Saprolegnia and Achlya); and Lagerheim ('00) on Monoblepharis, to show how rapidly our knowledge of the cytology of the Oomycetes has grown in the last decade of the nineteenth century. Little, however, has been done for the genus Pythium since the time of Pringsheim and De Bary ('87), to whose fundamental work it is no longer necessary for us to refer at length. Ward ('83) alone in this country seems to have paid attention to the genus, and his [Annals of Botany, Vol. XV. No. LVIII. June, 190r.] 
observations are practically confirmatory of those already made by De Bary. Although the microscope has been considerably improved during the last twenty years it is only just to say that the most recent observations on living material add little to the knowledge handed down to us by the older observers.

The only observations of importance on the karyology of Pythium, founded on the examination of fixed and stained material, are those of Fisch ('85) and Dangeard ('92).

Fisch states: 'Im jungen Oogonium, vor der Oosphärenbildung, sind ziemlich regelmässig 10-20 Zellkerne anzutreffen. Bei der Bildung der Oosphäre rücken sie zusammen, bis sie dicht aneinander liegen, und verschmelzen dann zu einem einzigen ziemlich grossen Eikern. In der Antheridialzelle habe ich immer nur einen Zellkern gefunden, bezweifle aber nicht, dass auch mehrere vorkommen können, die aber dann sicher vor der Befruchtung zu einem einzigen verschmelzen. Der Zellkern der Antheridialzelle wandert mit dem Gonoplasma in die Oosphäre über und verschwindet hier mit dem Eikern.' At the time Fisch wrote this it appears to have been quite the fashion to assume that a multinucleate organ became uninucleate by a process of wholesale nuclear fusions. The process of fusion was often definitely described, as by Fisch in the case before us. Careful observations have, however, shown that in many cases at least, e.g. Vaucheria, Peronospora, Cystopus, Saprolegnia, and Achlya, no such fusions are demonstrable, and that the uninucleate condition is reached in quite a different fashion. It is not difficult for the experienced botanist to realize how such errors of interpretation can arise. Even with the most refined of the modern methods it is often difficult to get thoroughly satisfactory proofs of the behaviour of the nuclei in any one case. Wager ('00) has indeed felt himself in a position to question the tenability of Fisch's view. He says, 'It is probable that the mode of fertilization described by Fisch for Pythium will be found to be untenable.' His view is a just one, but it is as well to bear in mind that great differences in the karyology 
of species of the same genus (as at present defined) may occur, as has been well shown recently in the case of Cystopus.

It would be interesting to know the exact meaning attached by Fisch to 'verschwindet' in the last line of the quotation. For nuclear fusion he uses the verb 'verschmelzen,' which is the usual term. It is noteworthy that in bad preparations the male and female nuclei are very difficult to demonstrate. They are apt to disappear from sight altogether. It is possible that Fisch never really traced in Pythium the nuclear fusion characteristic of fertilization. It is certain that in one species of Pythium at least no such fusions as those described by him take place.

Dangeard ('92) says : 'Le Pythium proliferum possède également de nombreux noyaux, soit dans les oogones, soit dans les anthéridies.' The observations recorded in this communication show that Dangeard's view, which so far as it goes does not materially differ from that of Fisch, is a correct one.

My work on Saprolegnia and Achlya, especially that part of it which dealt with the mode of fertilization and the degeneration of nuclei, made me anxious to study some member of the Oomycetes in which there was no question as to the actual sexuality, and where moreover one could follow the course of degeneration in indubitably degenerate nuclei. The Peronosporaceae offered the right kind of material.

Functional sex is universally admitted to be characteristic of this group. The periplasm might be expected to furnish the degenerate nuclei. That the genus Pythium is, as Fischer ('92) points out, a difficult one, with a considerable number of 'critical' species, in part at least, very badly defined; that nevertheless it has been selected to furnish type plants in two well-known and highly esteemed textbooks; that its study has been specifically introduced into more than one syllabus of elementary botany (or biology); and above all, as already pointed out, that a detailed knowledge of its karyology was still a great desideratum-furnished ample motives for its selection as the subject of a thorough investigation. 


\section{Trow.-Observations on the Biology and}

Most botanists engaged in actual teaching are probably familiar with certain difficulties which attend the practical study of the genus. In my own experience Pythium de Baryanum was commonly met with on dying cress-seedlings a few years ago. It is said that the spores of this species are universally present in the soil of gardens. Be that as it may, it has not put in an appearance at Cardiff during the last four years, notwithstanding repeated (annual) efforts made to secure it. Pythium de Baryanum is apt to be displaced by allied forms, and these are, as a rule, much less suitable for teaching purposes. In fact, many of them, owing to the delicacy of their mycelium and the irregularity with which the reproductive organs make their appearance, are almost, if not quite, useless for the purposes of demonstration to beginners. Even with so good a type as $P$. de Baryanum young students find it most difficult to make passable fresh preparations from infected cress-seedlings. It is not generally recognized, however, that the genus possesses a number of species which are pure saprophytes, and that of the remainder many can be readily cultivated as saprophytes. The parasitic species offer for most purposes no advantage over the saprophytic ones, for there is little to interest us in the attack of the parasite on its host in this case. Indeed in many species of Pythium the parasite apparently attacks its living host in just the same way that the saprophyte attacks the dead organic matter. The saprophytic species are, however, much easier to work with than the parasitic; for (I) dead organic matter is more easily procurable than living organic matter in the form of seedlings, and (2) suitable dead organic matter can easily be sterilized, while it is very difficult, if not impossible, to sterilize such objects as living seedlings, and (3) dead organic matter can be kept in the sterile condition for long periods with ease. So great are the advantages that teachers would do well to discard the haphazard methods now in vogue of securing cultures of parasitic species (frequently mixed), and provide themselves with a pure culture of a suitable saprophytic species, from which at any time 
abundant supplies of material could be obtained for demonstration.

The method adopted by me to secure material for investigation was the well-known one of growing seedlings in the presence of excess of water, both in the soil and in the air. Garden soil was obtained from various sources in the neighbourhood of Cardiff and sowings of cress made in it in the usual way. The seed pans were kept in a closed cold frame, which was drenched with water twice a day. Most of the seedlings, as they came up, of course 'rotted off,' and furnished the Pythium material. Somewhat to my surprise all the seedlings did not perish. It would be interesting to know the reason. The parasitic species of Fungus which presumably caused the death of the seedlings were very unsuitable for further examination. The mycelium was very delicate, and the reproductive organs were found either in small numbers or were conspicuously absent. Pythium de Baryanum was not seen. Some of the most suitable species were transferred to Petri dishes and cultivated on fresh seedlings in abundance of water. The result was disappointing. No single suitable species was secured.

In July, I899, however, a very rotten cress-seedling, which was lying prone on the saturated soil, was taken for examination. The stem was found on careful teasing to contain numerous spores. The spores were transferred to a coverglass and a moist chamber culture set up, using for nutrient material a fragment of boiled cress cotyledon. Germination took place at once, and a good culture was obtained. This was transferred to a Petri dish and a larger culture made on two or three boiled cress-seedlings. Growth was luxuriant: in a few days a fine mycelium filled the dish and before the end of the week there were numerous sexual organs present and even ripe oospores. This culture furnished the material for all the subsequent ones. Further moist-chamber cultures were set up, using a single spore as the starting-point, and the life history was worked out in detail from the germination of the asexual spores ('conidia,' as we had better call them) 


\section{Trow.-Observations on the Biology and}

and oospores to the formation of new conidia and ripe oospores.

In August, 1900, it appeared advisable to attempt to secure a really pure culture, i. e. not simply a culture of a single species of Pythium, derived from a single spore, but a culture which in addition was free from all other organisms whatsoever. Two or three species of small Amoebae which multiplied by division and encysted with the greatest regularity in the moist-chamber cultures, some Infusoria and Monads were got rid of by setting up a series of moist-chamber cultures. A culture, while still fresh and vigorous, was thoroughly washed with sterilized water and a small fragment used to inoculate a second one, the process being repeated a considerable number of times. Bacteria however obviously still remained, and it was necessary to find some other means of getting rid of these. The method used by Klebs to isolate Saprolegnia mixta was tried and much time consumed in the process, but to no avail, for the Bacteria flourished on the nutrient gelatine, and the Pythium made no growth at all. An attempt was next made to check the growth of the Bacteria by means of acids. A culture on sterilized cress-seedlings in a Petri dish was set up, using a $\mathrm{I} \%$ solution of acetic acid instead of water. No growth of any kind took place in this, either of Bacteria or Pythium. Before proceeding to test the effect of other organic acids and weaker solutions, an experiment was made by setting up a culture on the acid leaves of rhubarb. Very fine cultures were produced in this way practically free from Bacteria. But for a fortunate and almost accidental observation, I should no doubt have spent much time in making and maintaining a pure stock culture by the use of rhubarb leaves. In cultures of the Fungus on bits of cabbage leaves, parallel to those on rhubarb leaves, it was noted that if the leaf projected above the surface of the water in the Petri dish, the mycelium in very luxuriant cultures developed a slight aërial growth. It was obviously possible to exaggerate this by favourable conditions, and, by means of cuttings taken from it, obtain the pure infecting material that 
was required. Accordingly chunks of potato, carrot, and turnip, paste made of starch, flour, pea-meal, and various other materials, were sterilized in suitable glass pots and inoculated with the relatively pure material obtained from the rhubarb leaf cultures. On the second day after inoculation there was a growth of pure white aërial mycelium on potato, carrot, and turnip a centimetre in height, which on the following day had increased to almost an inch. The mycelium indeed quickly filled the whole pot. It was obvious that a very simple way of obtaining a pure culture had been found. It was only necessary to sterilize potatoes and inoculate them with a trace of the aerrial mycelium. This was done, and the pure culture thus obtained provided all the material upon which the more important results were worked out.

Such pure cultures can be obtained, no doubt, with ease in many species of Pythium, and it is to be hoped that in the future the method described will be largely utilized.

It is perhaps of interest to add that the attempt to cultivate the Fungus on different kinds of paste yielded negative results.

\section{ObSERVATIONS MADE ON Living MATERIAL.}

As already indicated, this species of Pythium has been studied in three distinct types of cultures :-(I) Moist-chamber cultures, the nutrient material being generally the legs of house-flies; (2) Petri-dish cultures, the nutrient material being generally dead flies or bits of cabbage leaves; and (3) Glass pot cultures, the nutrient material being boiled potato.

The glass pots were cylindrical, $4 \mathrm{~cm}$. high, $6 \mathrm{~cm}$. in diameter, and of a capacity of about $100 \mathrm{c} . \mathrm{cm}$. In the first two types the mycelium develops, with rare exceptions, entirely under water and so is aquatic; in the third the mycelium grows out into the air, and so is aërial. In all cases certain branches of the mycelium penetrate the nutrient substratum, and thus are intramatrical, but the greater portion of the mycelium is extramatrical. The intramatrical parts do 


\section{Trow.-Observations on the Biology and}

not differ from the extramatrical in any material way. Both may bear the reproductive organs. There is no differentiation of rhizoids or haustoria.

The details of the life history were worked out almost entirely with the help of the moist-chamber cultures. This was necessary not only as a means of determining the systematic position of the species, but especially as a guide to the proper sequence of the series of sections required to illustrate the karyology.

No attempt will be made to describe the results in the order in which they were obtained, but rather in the way in which they can be most easily followed, and in the order in which they could most quickly be verified.

Germination of the conidia. The conidia are either terminal and spherical or intercalary and barrel-shaped. If they are placed in distilled water they remain at rest for an indefinite period. If placed in a drop of cabbage water they germinate at once, one or more germ-tubes putting in an appearance with the greatest punctuality in about an hour's time. So regular is this that if thousands of conidia are sown at the same time it is generally impossible to find a conidium with a germ-tube three-quarters of an hour later, or a conidium without one after two hours. Germination likewise takes place if a fly-leg is added to a drop of tapwater containing conidia, but not quite so regularly. Figs. I and $2(\mathrm{Pl} . \mathrm{XV})$ fully illustrate the process in the case of two conidia which were placed in cabbage-water at 9.50 a.m. The germ-tube makes its appearance very suddenly, and its apex is filled with hyaloplasm. Sometimes, as in Fig. I $b$, an elongated vacuole makes its appearance, and then germ-tubes generally appear opposite its poles. In a few cases there have been observed faint indications of a segmentation of the protoplasm, as if zoospores were to be formed. No zoospores, however, have been seen at any time, and it may be regarded as certain that the conidia are no longer capable of producing them; for (I) there is no indication of a terminal beak such as is usual in sporangia, (2) no germination takes place in 
distilled water, (3) tube-germination takes place, although slowly and irregularly, in material placed in running tapwater, (4) in suitable nutrient solutions each conidium may give rise to four or five germ-tubes whose place of origin is quite indefinite, and (5) empty conidia have never been seen, although very numerous experiments have been made on germination. There can be no doubt that in this species the conidium has completely lost its sporangial character. Pythium furnishes us with a series of forms- $P$. megalacanthum, $P$. de Baryanum, $P$. vexans, and $P$. ultimum, roughly parallel to the corresponding series in Peronospora described by von Tavel ('92), viz. P. nivea, $P$. densa, $P$. Lactucae, and $P$. Radii, in which the stages in the conversion of a typical sporangium into a conidium are preserved for us.

The conidium generally becomes vacuolated if kept in distilled water, or in exhausted nutrient solutions. They have been kept under observation for seven months. Whatever may be the age, germination takes place at once in appropriate nutrient solutions.

Growth of the mycelium. Growth is extremely rapid, as may be seen at once by reference to Figs. I and 2. The hyphae indeed, in a few hours, grow out of the drop altogether.

Branching is of course monopodial, but very irregular. In order to keep the same culture under observation for any period of time greater than twenty-four hours, it is necessary to remove the cover glass, and by suitable manipulation bring the wandering hyphae once more within the limits of a small drop of nutrient solution. The hyphae are so delicate that it is difficult to do this without causing serious injury. Under careless manipulation the protoplasm may be seen coursing down the older hyphae in the most violent way. Such injury however is not irreparable, for the protoplasm in the apical parts is fairly stable and not readily destroyed, and fresh growth takes place at once. In about two days in warm summer weather (day temperature averaging about $22^{\circ} \mathrm{C}$.) the small drop is traversed in all directions by a net- 


\section{Trow.-Observations on the Biology and}

work of hyphae forming a felt-like mycelium, and the formation of the reproductive organs commences. These are of two kinds, asexual and sexual, of the type characteristic of the genus, and they appear in abundance in these cultures in the usual succession. We have first a crop of conidia and then a crop of oospores, the change from one type to another being quite gradual however, so that on adjacent hyphae conidia and oogonia may be seen in course of development at the same time.

Formation of the conidia. The end of a branch stops growing in length, but grows in breadth so as to produce a spherical head; this increases in size, and is finally cut off from the hypha which bears it by a transverse wall. Intercalary conidia are formed in a similar manner. The protoplasm of the conidia is about as dense as that of the young hyphae, and may or may not contain one or more vacuoles. Thus a conidium is simply a terminal or intercalary swollen portion of a hypha, cut off from the rest of the mycelium by one or two transverse walls.

Formation of the sexual organs. An oogonium is at first exactly like a conidium. Even when it is cut off from its supporting hypha by a transverse wall, it requires some experience to recognize it. It appears of a darker colour, due, no doubt, to the reserve materials present, but this is not apparent to the uneducated eye. Even a novice, however, is able to recognize an oogonium when it is accompanied by an antheridial branch or an antheridium. Fig. 3 gives the result of a study of the formation of the sexual organs up to the complete development of the antheridium. The observations commenced at 9.20 a.m. upon the two young oogonia shown in Fig. $3 a$. The upper of these alone reached maturity; the protoplasm of the lower and younger was used up to provide the material for the development of the older. In undisturbed cultures in Petri dishes this never happens, so that the anomaly is no doubt due to the necessary preliminary manipulation of the preparation. In four hours the oogonium had grown to its full size. At about $2.5 \mathrm{p} \mathrm{m}$. the antheridial 
branch suddenly made its appearance, immediately below the oogonium, and thirty minutes later, as shown in Fig. $3 e$, the antheridium was fully formed. Nearly the whole of the remainder of the protoplasm in the aborted oogonium was used up in the formation of the antheridium. It is noteworthy that the oogonium occupies a terminal position until the antheridium is formed, when it is forced into a lateral one, a phenomenon common enough in cymose growths of very different kinds. Such displacements, combined with eccentricities of behaviour induced by the manipulation of the preparations, make continuous observations very tedious, and often practically impossible. The details of fertilization cannot be followed in organs orientated as in Fig. $3 e$. Fig. 4 gives the result of a study of the maturation of the sexual organs and of the process of fertilization. The oogonium represented in Fig. $4 a$ was placed under observation and watched until, at about 7.55 a.m., the antheridial branch made its appearance. It was kept under constant observation until $2.0 \mathrm{p} . \mathrm{m}$. and drawings made at frequent intervals. It would serve no useful purpose to describe in detail the changes observed from time to time in the protoplasm, for we appear to have no clue to their significance. It would be just as unprofitable as to describe the different shapes assumed by an Amoeba. The figures represent all that is of interest in the present state of our knowledge. We note that the appearance of the protoplasm in the oogonium changes considerably during the first three hours. Denser patches appear and disappear. The differentiation of the oosphere does not take place in the manner described by De Bary for Pythium gracile, or by Ward in the species investigated by him. Further, there is no differentiation of gonoplasm and periplasm in the antheridium.

The denser protoplasm, including all the particles of reserve material, migrates towards the centre of the oogonium, leaving behind for a time an inconspicuous, faintly granular layer between it and the wall of the oogonium, as shown in Figs. $4 e$ and $4 f$. De Bary and his followers regarded the 
dense central mass as the egg, and the clear peripheral layer as the periplasm. The central mass is in continuous movement, but tends to round itself off more and more, though it never acquires a smooth outline like that of the eggs of the Saprolegniaceae. Moreover the delicate peripheral layer completely disappears as represented in Fig. $4 g$, so that if we accepted the current view as to the significance of the central mass, we should have to admit that the periplasm disappears during the differentiation of the egg. The warted appearance of the central mass is very characteristic of this stage, and is apparently due to an accumulation of reserve globules. The study of sections proves what the examination of the living material leads one to suspect, that the central mass includes both egg and periplasm, and that the egg is completely masked by a dense mantle of periplasm containing globules of reserve material.

Turning our attention to the antheridium, we note that its growth is rapid, and that after a time two or three granular aggregations make their appearance in it. These may be nuclei, but it was impossible to furnish proof of their real nature. As the central mass begins to form in the oogonium (see Fig. $4 e$ ), a fertilization-tube becomes apparent, connecting the central mass with the antheridium. This gradual disclosure of the fertilization-tube has been generally interpreted apparently as its growth. There can be little doubt that it was formed before the differentiation of the oogonial contents began, as I have never been able to get a view of its apex, and have thus never been able to trace its growth. Different species of Pythium may behave differently in this respect. Certainly De Bary's figure of Pythium gracile suggests that such is the case, and the point thus deserves further investigation in other species.

Fertilization. The question of fertilization is a curious one. It seems generally admitted that the process of fertilization can easily be followed in this genus. Authors, however, apparently mean by this that they can trace a slow migration of the protoplasm down the fertilization-tube. 
This slow movement may last for from one to two hours according to De Bary. In Fig. $4 g$ two granules are represented in the fertilization-tube. They slowly passed on down the tube and necessarily disappeared from sight before they reached its end, that being concealed from view. In Fig. $4 h$, the progress made in the emptying of the antheridium is scarcely noticeable, while in Fig. $4 j$, drawn half an hour later, it is practically completed. The actual process of fertilization may have taken place at any time between I.० p.m. and 2.0 p.m. It almost certainly takes place quickly. What the significance of the gradual emptying may be it is difficult to say. Some evidence has been collected to show that much of the antheridial contents pass into the periplasm. On three occasions a little mound of protoplasm collected around the indentation made by the fertilization-tube and streamed away over the central mass from that point. It is significant that the egg rounds itself off and appears covered with a membrane before the last traces of protoplasm leave the antheridium. The last visible particles, as in Fig. $4 j$, do not pass out as such. They appear to be dissolved in situ, and so slowly vanish.

Observations on the living material do not suffice to prove the existence of fertilization, much less the mode in which it is effected. We have in fact the usual difficulty to contend with, the large female gamete is too dense to allow us to watch the entry of the small male gamete. It seems abundantly clear, however, that we have no justification for recognizing a differentiation of the contents of the antheridium into gonoplasm and periplasm. A study of stained sections is absolutely necessary for the proper interpretation of the phenomena observed in living material.

Maturation of the oospores. The maturation of the oospores may be completed in about twenty-four hours after fertilization has taken place. Three points of interest have to be noted. The original thin membrane covering the young oospore increases considerably in thickness by the deposit on the inside of a thick layer of some kind of cellulose. The 
wall becomes distinctly two-layered, and as it grows older it acquires a yellowish colour. The so-called oil globule, better named reserve globule, develops in the middle of the protoplasm, and lastly between the central globule and the wall a large nucleus makes its appearance. Fig. 5 shows successive stages in maturation in the case of an oospore which ripened very slowly. The egg was fertilized on $29 / 8 / 99$ at about 5 p.m. The oospore took more than three days to ripen.

The following summary will serve to show roughly the time occupied by this species of Pythium in passing through the various stages of development :-

For the growth of the mycelium . . . 48 hrs.

For the completion of the development of a half-grown oogonium, reckoning up to the first appearance of the antherial branch . $4 \frac{3}{4}$, For the formation of the antheridium . . 30 to $45 \mathrm{~min}$.

From the complete formation of the antheridium to the commencement of oosphere differentiation .

$2 \frac{1}{2}$ hrs.

From the commencement of oosphere differentiation to the first noticeable movement of protoplasm in the fertilizationtube (act of fertilization?) . . . 2 "

From the act of fertilization to the rounding off and definite limitation of the oospore.

For the maturation of the oospore . . . 24 "

Ripe oospores may, as a matter of fact, be obtained in abundance on the fourth day in suitable cultures. Threeand four-day cultures would then be generally suitable for the preparation of serial stained sections, and were indeed most frequently used.

Germination of the oospores. The oospores germinate as soon as ripe, or after a period of rest extending to seven months. The process of germination resolves itself into two stages, which are in my experience generally separated by a period of rest. In the first stage the oospore becomes a 
conidium, in the second this conidium develops one or more germ-tubes. To provide suitable material for sectioning, it was necessary that large numbers of oospores should be made to germinate together. After many futile attempts, in which the effects of variations in temperature and culture media were tried, success was achieved as follows :-

A mass of oospores was allowed to stand for some days in distilled water. These were then placed in running water and examined from time to time. Large numbers of oospores germinated. Upon examining such oospores it was found that (I) the thick inner layer of the wall of the oospore dissolved, (2) the fatty globule disappeared together with the lateral nucleus, and (3) the protoplasm increased in amountno doubt at the expense of the reserve materials, and became more coarsely granular. The oospore in this changed condition resembles a conidium so closely that its real character is recognizable only by its position inside the wall of the oogonium. In running water no further development takes place as a rule, but if such material be transferred to cabbagewater the germination is completed by the outgrowth of one or more germ-tubes, such as are produced by ordinary conidia.

Once again it is to be noted that under no circumstances is there the slightest tendency to the formation of zoospores. Whatever the age of the oospores, the nutrient medium in which they are placed, or the temperature to which they are subjected, tube germination takes place or no germination at all.

However the conditions which regulate the germination of the oospores still require further investigation, as the following considerations will show. The method outlined above does not always succeed. The reasons for the failures have to be determined. Further, when the transference of the halfgerminated oospores to the cabbage-water is made it is found that only a very small percentage ( 5 to 10 ) succeed in developing germ-tubes. The remainder burst, liberate a portion of their contents under considerable pressure into the 


\section{Trow.-Observations on the Biology and}

cavity of the oogonium, and then perish. A profile view of the bursting has not yet been obtained, although about six specimens have behaved in this way under direct observation. For these reasons figures illustrating the germination of the oospores are for the present withheld. The actual outgrowth of the germ-tubes has been traced under the microscope in about thirty cases, occurring in two sets of cultures in two successive years.

Interesting differences presented by the three types of cultures. The foregoing remarks refer almost exclusively to observations carried out on moist-chamber cultures. These are apt to be abnormal for the reasons already given, and it was thought wise to grow the plant in Petri dishes in abundance of water to check the results obtained by direct observations of small cultures under the microscope. In these cultures dead house-flies, which had been kept in an air-dry condition for twelve months, and bits of cabbage leaves were generally used to furnish the requisite nutrient material. Both kinds of food were sterilized by steaming for an hour on each of three successive days. Having set up at least sixteen series of Petri-dish cultures, each with four or more examples, one can safely make the following generalizations. The cultures on cabbage leaves were more luxuriant than those on the flies, and they normally produced oospores only. The house-fly cultures, on the other hand, produced with few exceptions conidia only. In cabbage-leaf cultures conidia might occasionally be seen, but always in relatively small quantity, and similarly in house-fly cultures a few oogonia might be found. By using these two types of cultures for imbedding, it was obviously easy to avoid confusing sections of oogonia and conidia. Such an aid was, however, found to be quite unnecessary, for these organs are much more readily distinguished in the stained than in the fresh condition.

It has already been said that pure cultures were made in August, I900, on potatoes. These cultures were remarkable not only for the luxuriant development of an aerrial mycelium, but for the fact that they remained sterile for weeks. At 
first indeed it was thought that they would prove permanently sterile. However, a culture six weeks old acquired patches of golden yellow colour, and an investigation of the reason for the change led to the discovery of both kinds of reproductive organs-conidia and ripe oospores, chiefly the former. Many of the cultures perish through drought before producing spores. We have here no doubt an interesting example of the effect of abundant food material, as already noted for example by Klebs ('99) for Saprolegnia mixta and by Goebel ('00) in the case of the protonema of Bryum psendotriquetrum. The last culture set up was the thirty-first of a series, each of which was obtained by inoculation with a sterile fragment of its predecessor. The mycelium in this last culture is a direct descendant (by vegetative propagation) of that first obtained in August nearly five months ago, and still shows its tendency to remain sterile, while the abundant supply of nutriment remains unexhausted.

These interesting differences in the behaviour of the plant under different external conditions require further investigation. I hope to be able, at some future date, to give a more satisfactory account of them in a paper on the physiology of the species.

Dissemination of the spores. The conidia and oospores (or oogonia) are set free by the rotting away of the old exhausted mycelium. In pure cultures they may remain attached apparently for an indefinite period. In nature no doubt the spores are liberated and disseminated by the disintegration of the rotten substratum upon and in which they are found. No experiments have yet been made on their powers of resisting drought. The spores, however, do not appear to be adapted for dissemination by the wind. Potatoes have been purposely left exposed in the laboratory in places where enormous numbers of spores had been produced, yet no spontaneous infection took place. The mode of dissemination indicated is, however, effective enough for a plant which vegetates in the surface soil on rotting vegetable and animal matter. 
Relation of growth to temperature. The cultures were carried on at first during the summer months, and growth and development was, as has been said, very rapid. After a lapse of two months fresh cultures were started-in November, I899-and these made very poor growth, and the reproductive organs appeared only after the lapse of a considerable timea week or more. A few experiments sufficed to prove that this was entirely the result of the low temperature. Potato cultures do not produce an appreciable aërial growth at room temperature during our winter, so that in the winter months the cultures have to be kept growing in the incubator. Growth is very good, at its optimum probably, at a temperature of $25^{\circ} \mathrm{C}$. The incubator is maintained at $24^{\circ} \mathrm{C}$. to $26^{\circ} \mathrm{C}$. Growth is stopped at about $35^{\circ} \mathrm{C}$. The optimum, minimum, and maximum temperatures have yet to be accurately ascertained, but we already know enough to realize that the plant is adapted for a summer rather than a winter life in our climate. This is the more remarkable, as our wet, mild winter would appear to furnish it with a very suitable environment.

Experiments to determine its capacity to vegetate as a parasite. From the outset the plant appeared to be a pure saprophyte, but as it was of importance for taxonomic purposes to determine the point accurately, two sets of experiments were instituted. In the first, cultures of cress-seedlings were raised in sterilized soil in a damp atmosphere under bell jars. These were infected with healthy cultures of the Fungus, chiefly by laying the cover-glass cultures on or in the soil in contact with the plants. These cultures of the Fungus were not absolutely pure, and free watering was resorted to, as at that time the power of the mycelium to grow in the air was not known. No single case of 'rotting off' occurred in the six experiments instituted. Indeed the cress developed quite luxuriantly under these conditions. In the second, cressseedlings were uprooted and laid in water in sterilized Petri dishes and cultures of the Fungus added. These cultures were to a considerable extent under microscopic control. No infection and little growth took place. The cress-seedlings 
remained fresh for days. It must be remembered that if boiled cress-seedlings are used the material is attacked at once, and vigorous growth is the result. The species is clearly a true saprophyte.

\section{ObServations on Serial Sections.}

Preparation of the material. At first Petri-dish cultures, three, four, or more days old, were taken and examined in situ under the microscope. If in suitable condition they were fixed in Hermann's fluid, while still in the dish and under microscopic control. They were then passed into paraffin through the medium of xylol, and the material was finally sectioned $5 \mu$ thick and stained with gentian violet. A complete series of preparations was found, illustrating all stages in the cytology, and then it became evident that the method was not an absolutely satisfactory one. The nuclei could not easily be followed at the stage immediately succeeding fertilization, as had been the case indeed in previous years with Saprolegnia and Achlya, and in addition there was a difficulty in following the details in the maturation of the oospores. The preparations used to furnish the illustrations were with four exceptions made as follows:-

Absolutely pure cultures were grown in Petri dishes and fixed under microscopic control by immersion in Flemming's stronger solution for periods of five hours or more. The blackening was removed by hydrogen peroxide and the dehydration carried out with great caution. No collapse took place. Here the microscopic control came to an end. The material was transferred to paraffin through the medium of xylol. The alcohol was gradually displaced by xylol and the xylol by paraffin. Notwithstanding these precautions, shrinking and some amount of collapse took place at this stage, although curiously enough chromacetic acid material passed through the imbedding oven at the same time under precisely similar conditions showed no shrinking of any kind. Sections were cut of $5 \mu$ thickness and stained with gentian violet. 


\section{8}

\section{Trow.-Observations on the Biology and}

For purposes of comparison other methods of fixing and staining were used. Mercuric chloride solutions, platinic chloride solutions, and acetic alcohol were used for fixing, in addition to those already mentioned. The best results were obtained with Flemming's solution, chromacetic acid, and Hermann's solution, and of these the first two were somewhat better on the whole than the third. Flemming's solution preserved the details of the protoplasm better than the chromacetic acid, and the nuclei could be followed at all stages with almost equal facility. The stains chiefly used were gentian violet, haematoxylin, and safranin. Gentian violet gave excellent results. Safranin proved useless although much time was expended over it. With gentian violet or iron-alum haematoxylin it is possible to decolourize the cytoplasm and yet leave the whole nucleus either deep violet or black. The counting of the nuclei is very easy in such cases. By further differentiation the detailed structure of the nucleus is disclosed. With safranin diffuse staining was alone possible. After many experiments with two kinds of safranin (Grübler's), using the stain alone and in combination, no single section was found with good differentiation.

It is probable that equally good results would have been obtained with the material fixed in chromacetic acid, but time was not available for the detailed study of a third series of sections. It is noteworthy that although Flemming's solution kills the protoplasm instantly, and blackening is observable in a minute or two, very poor staining results were obtained when the time of action was limited to an hour. As Flemming has pointed out the special action of the chromic acid is a slow one.

Of the two series of sections fully examined, one was of material obtained from impure cultures in which Bacteria were present, the other was of material from absolutely pure and very fine cultures. These series were fixed and stained in different ways, but the results were always concordant. The pure cultures were of advantage, however, with respect to one point, as will be seen later. The illustrations, with 
four exceptions, as already stated, are based upon preparations made from the pure cultures, fixed with Flemming's stronger solution for five or more hours, and stained with gentian violet.

The sexual organs and oospores. Figs. 6 to 45 represent consecutive stages in the development of the sexual organs, in fertilization, and in the maturation and germination of the oospores. The sequence may not be absolutely correct, but such errors as may unavoidably have crept in must be of small moment. Comparisons should be made with the corresponding figures representing the condition in the living material. Relative age may frequently be determined fairly well by the size of the organ, the distribution of the contents, and the thickness of the cell-wall.

At first it was intended to make careful countings of the nuclei in the different stages. This idea was soon abandoned, for even with sections $5 \mu$ thick the number of available sections in a series was generally but three, and so short a series is difficult to follow accurately because of the rapid change in the appearance of the sections. Indeed one has not only to find suitable sections, but sections so placed that there is no danger of passing from one oogonium to another. Moreover it was found that the median section of three was quite sufficient to give one a clear idea of the condition of the remaining two, and so of the whole. It is necessary perhaps to add that, nevertheless, a series of sections was generally examined before a median one was adopted for detailed study. The reader who has the drawings of the median sections before him has therefore a full opportunity of criticizing the views founded upon their examination. Had drawings of the adjacent sections been added in each case no additional feature of importance would be noticeable.

Fig. 6 represents a half-grown oogonium. The nuclei are small. The number is in this case exceptionally large, but the remaining two sections only contained four additional nuclei. The number of nuclei in a young oogonium is very variable, ranging from twelve to twenty-five or thirty, and the 


\section{Trow.-Observations on the Biology and}

distribution is by no means uniform. The oogonium has no central vacuole at any stage in its development.

In Fig. 7 the oogonium is completely formed, its basal wall being already present. The protoplasm is coarsely reticulate. The nuclei are relatively large and have arranged themselves at the periphery of a hollow sphere. This increase in size of the nuclei is in preparation for an indirect division. The arrangement of the nuclei in a ring prefigures the division of the contents of the oogonium into oosphere and periplasm. In another oogonium in the same stage of development, which had a diameter of $18 \mu$, the nuclei were counted in the three sections. The numbers were ten, three, and one, making a total of fourteen.

In Fig. 8 the antheridium is shown in contact with the lateral wall of the oogonium. A 'receptive spot' has been formed by the oogonial plasm, somewhat similar to, although perhaps not so highly differentiated as those described by Wager ('96, '00) in Cystopus and Peronospora, and Stevens ('99) and Davis ('00) in Albugo (Cystopus) Bliti and Albugo (Cystopus) candida. A small nucleolus is visible in the oogonial nuclei at this stage.

In Fig. 9 the formation of the egg has commenced, the fertilization-tube is in contact with the dense protoplasm, and the ring-like grouping of the nuclei is very noticeable. The nuclei are in metaphase, the spindles being plainly seen in the oogonium and antheridium. One oogonial nucleus is inside the ring formed by the others. The number of separate chromosomes visible in a polar view of one of the dividing nuclei is 8 .

In Fig. Io the nuclei are in anaphase, and the connecting threads of the achromatic figure are clearly visible. The egg is outlined, and one nucleus only is dividing inside it ; the rest are in contact with its outer surface.

In Fig. I I the fertilization-tube has penetrated the periplasm quite far enough for its apex to be invisible, except with the aid of sections. Here two nuclei are still in the egg, and - nuclear division is not so far advanced as in Fig. 9, although 
in that case no differentiation of the egg had taken place. It is obvious that the development of the egg, growth of the fertilization-tube, and nuclear division are, to some extent at least, independent processes.

In Fig. I 2 the egg is much more clearly outlined, and contains one nucleus probably in metaphase. In Fig. I 3 the fertilization-tube is in contact with the egg, which however is by no means ready for fertilization. The periplasmic nuclei have divided and are obviously smaller and more numerous. The egg contains four nuclei, the result of a recent division, one division indeed being not quite complete. The peripherally placed nuclei no doubt pass into the periplasm. Beautiful spindles are seen in the antheridium, showing that the nuclear divisions in the male and female organs are not quite synchronous.

In Fig. I4 the egg is relatively large, and its protoplasm is much less dense. The periplasm is thinner, but its nuclei show no sign of degeneration. The egg contains two nuclei, the one central and the other peripheral. In Fig. I5 the centre of the egg is occupied with a mass of protoplasm which stains more deeply than the remaining parts. This corresponds to the 'coenocentrum' of Stevens ('99). The detailed discussion of Swingle's ('98) view that it is an organoid of the cell, whatever that may exactly mean, would scarcely be a profitable one. It may be compared to a whirlpool in a river, for it has a form, though an inconstant one, and probably no real material existence. It is no doubt, as Stevens appears to have recognized, an expression of the forces acting at the centre of the egg rather than of the matter present there. The receptive spot is probably of a similar nature. It is convenient for purposes of description at all events to give such recognizable objects distinctive names. Although the term coenocentrum is not free from objection, it is adopted provisionally here as a useful descriptive term. The boundary between egg and periplasm is very sharply defined in this figure. The end of the fertilization-tube has penetrated into the egg. 


\section{Trow.-Observations on the Biology and}

although the nuclei in the antheridium are still undergoing division.

In Figs. $16 a$ and $16 b$, representing adjacent sections of the same oogonium, the 'coenocentrum' is present and the egg fully differentiated. The periplasmic nuclei are relatively large, and the fertilization-tube just reaches to the egg. Sections like these when compared with those represented in the two preceding figures arouse the suspicion that there may be a double division of the nuclei. The weight of the evidence, based upon countings of the nuclei, is against a second division. Such differences as are presented here we must regard, at any rate provisionally, as due to simple variation. In Fig. I 7 the egg is uninucleate but destitute of a 'coenocentrum,' yet the fertilization-tube has penetrated a considerable distance. The nucleus in the antheridium is in metaphase. In Fig. 18 the fertilization-tube is almost in contact with the female nucleus. Nuclear division in the antheridium is almost complete. One pair of daughter-nuclei are seen in the last stages of division.

In Fig. I9 we have before us apparently the very act of fertilization. The egg has now separated from the periplasm, and the 'coenocentrum' is very obvious. The fertilizationtube can be traced almost as far as the 'coenocentrum' and up to the posterior end of an elongated male nucleus. The wall of the fertilization-tube may be traced as a transparent membrane of measurable thickness through the periplasm up to the margin of the egg, but its continuation in the egg itself is no longer recognizable as a definite membrane. It must be remembered that such sections as these, stained to show the structure of the cytoplasm and nuclei and mounted in balsam, are not suitable for the study of the cell-membrane. The nature of the boundary line between the substance of the egg and the fertilization-tube which lies within it, must therefore, for the present at least, be left undecided. It is, however, abundantly clear from the preceding figures that the general view as to fertilization in Pythium, founded on De Bary's observations on living material, is for this species 
certainly, and probably for the others, an erroneous one. There is no separation of the antheridial contents into periplasm and gonoplasm. In the oogonium, the periplasm covers the egg with a dense mantle at the period of fertilization, and makes it impossible to follow the actual process in the living material. The passage of protoplasm down the fertilization-tube has been assumed to be a proof that the act of fertilization was going on, an assumption entirely unwarranted now that we know the central mass is not an egg, but an egg covered with a thick dense mantle of periplasm. Further examination of Fig. I 9 reveals the interesting fact that degeneration of the periplasmic and supernumerary antheridial nuclei has commenced. The degeneration is characterized by the assumption of greater density and great irregularity of form. The vesicular nuclei, in fact, appear to collapse.

The next figure is of a section of considerable interest. It and one other, unfortunately insufficiently noted and passed over before its importance was recognized, were the only sections found in this condition. Of other stages, with the exception of that in Fig. I9, many examples have been seen. The egg in Fig. 20 is only partially separated from the periplasm. It is uninucleate, presumably ready for fertilization, and is deeply indented by the inpushing of the fertilizationtube. That there is a definite boundary to the fertilization-tube in this case, is shown by the slight plasmolysis or shrinking which has taken place. The other section, incautiously regarded as anomalous, and lost after making a rough sketch of it, showed the egg quite free from the periplasm, but deeply indented on one side by a swollen fertilization-tube. There was the same shrinking as in the previous case, but the egg was binucleate. One nucleus, no doubt the female nucleus, occupied the centre of the egg; the other was just within the periphery of the egg at the bottom of the indentation, and immediately opposite the fertilization-tube, which however appeared to have a closed end. The inference drawn from these observations is that the fertilization-tube parts with a nucleus at its tip, just as a tube filled with a viscous 


\section{Trow.-Observations on the Biology and}

liquid may be easily made to part with a single drop from one extremity. This nucleus fuses with the egg at the moment of its liberation. The egg then rounds itself off, pushing out the thin-walled portion of the fertilization-tube to the periphery and so into the periplasm. A portion of the antheridial contents probably passes into the periplasm, the rest remains behind in the antheridium. The whole process probably depends upon, and can be explained in terms of, chemiotaxis, osmotic pressure, and surface tension.

Figs. 21 to 27 show important stages in the maturation of the oospore. In each case there are two nuclei. Hundreds of oospores have been examined in this condition, and all were binucleate. If a section proved to be uninucleate, as sometimes happened, one could with certainty predict that the remaining nucleus would be found in the adjacent section. It is noteworthy that the cell-membrane of the young oospore remains very thin and delicate throughout the period represented in these sections, which, however, is no doubt a short one. Nuclei in a degenerate condition may be found in the antheridium, as shown in Fig. 22, after the membrane of the spore is fully formed. The order of succession in this series is marked by one character only, that of the gradual disappearance of the periplasm. The collapsed nuclei degenerate rapidly. They are apt to form irregular figures, as shown in Figs. 22 and 23, and vanish altogether before the last traces of protoplasm have been dissolved.

The significance of these observations is perfectly clear. The whole of the periplasm is digested and absorbed by the young oospore, an actual increase in size of the latter being noticeable during the process. The explanation I ventured to give of the fate of the supernumerary nuclei in Saprolegnia and Achlya finds confirmation here. Working with pure cultures proved of advantage in this case. Under such conditions there could be no question of some outside agents like Bacteria acting as ferments and absorbing the products. The plant itself was the only possible agent concerned, and if we consider how rapidly the result is effected, and the growth 
of the oospore which simultaneously takes place, we may with safety conclude that the whole process of digestion and absorption is the work of the young oospores themselves. It is well to note that no appreciable thickening of the oospore-membrane takes place until the last traces of periplasm have disappeared. The first stage in the maturation of the oospores is marked then by the digestion and absorption of the periplasm by the growing oospores.

The second stage, represented in Figs. 28 to 32 , is marked by three distinct processes of differentiation, viz. the thickening of the spore membrane, the fusion of the male and female nuclei, and the development of the reserve globule. The primary membrane of the oospore remains thin and appears to become slightly cuticularized, staining deeply with gentian violet. New layers are, however, added on the inside at the expense of the protoplasm, until a very considerable thickness is reached. Whether we are justified in speaking of an exospore and endospore in this case is doubtful, for as we shall see, the very thick inner wall is essentially a mass of reserve material. The two nuclei approach each otheras indeed they do at an earlier stage, as may be seen by comparison of Figs. 25 and 28 -but the actual fusion is delayed for a considerable period. Apparently ripe oospores are sometimes found to contain two closely approximated nuclei, as shown in Fig. 32, but this is very exceptional. The ripe oospores are uninucleate, and uninucleate oospores may be found in cultures four days old. The actual fusion is not difficult to trace, as the nuclei at this stage are in the resting condition and fairly conspicuous objects. Three stages in fusion are represented in Figs. 29, 30, and 31. In the ripe oospores there is constantly to be found a globular mass which in the main gives the proteid reactions. This mass may have one large cavity in its interior, when its form becomes that of a hollow sphere; or it may have numerous small cavities, in which case it possesses a spongy character. The mass corresponds to the reserve globule seen in the living material. It has generally been considered to be of 


\section{Trow.-Observations on the Biology and}

a fatty nature. More probably it represents a complex aggregate of oils and proteids. Its thorough chemical investigation is much to be desired. Its origin has not been traced.

Figs. 33 to 40 illustrate sections of germinating oospores drawn specially to show the behaviour of the nucleus at this period, sections showing the reserve globule being consequently excluded. In Fig. 33 the large nucleus is at rest and has a conspicuous nucleolus. The reserve globule is shown in this case for the sake of comparison. In Fig. 34 the nucleus is in the spirem condition and the nucleolus still visible. In Fig. 35 the nucleus is in metaphase and the chromosomes may be approximately estimated. At one end of the spindle six can be counted. Such nuclei are practically indistinguishable from those seen undergoing karyokinesis in the sexual organs. It is not possible to make an accurate estimation of the chromosomes in each case, but the appearances all point to the numbers being approximately equal. In Fig. $3^{6}$ there are two nuclei undergoing division, and at this stage the inner wall of the oosphere is much thinner than before. The protoplasm obviously grows at the expense of the inner wall. In Figs. 37 and $3^{8}$ we have further solution of the wall and division of the nuclei.

In Figs. 39 and 40 the wall is thin and delicate, enclosing granular reticulate and vacuolated protoplasm and numerous nuclei. Six to eight nuclei may be counted in a single section. Additional nuclei would of course be found in the sections adjacent to those represented in Figs. 39 and 40 , but not in those adjacent to the ones represented in Figs. 33, 34, 35, and 36. Such sections of oospores as are shown in Figs. 39 and 40 could not be distinguished from those of conidia but for the presence of the oogonial wall. It is especially noteworthy that at this stage, as represented in Fig. 40, some of the nuclei appear to be double. Careful observations show that the double condition depends upon the presence of two central chromatic masses (not nucleoli). The most obvious explanation of this is that the nuclei are undergoing more or less 
direct divisions or fusions. Another explanation might be found in the supposition that the appearances were caused by two nuclei coming into contact with one another. We have to note, however, that the nuclear membrane is distinctly traceable as a definite line, sometimes dipping inwards so as to cause partial constriction, but never separating the two chromatic masses from one another. Further, the number of nuclei remains fairly constant when these abnormal nuclei are present. There is neither a diminution nor increase in their number, and indeed they appear in the reproductive organs only when these are at rest. At present it is therefore impossible to do more than regard them as nuclei with anomalous structure. The future may be able to throw light on their genesis and fate.

Figs. 4I to 45 illustrate sections of germinating oospores designed to show the fate of the reserve globule. Incidentally they show the changes in the wall and the nuclei at the same time. It is clear that the reserve globule becomes more spongy, breaks up into separate masses and gradually undergoes digestion, absorption, and assimilation. The last traces of this reserve material may be seen in the form of deeply stained granules in Figs. 44 and 45 .

We have still to consider the structure of the mycelium and conidia as traceable in sections, and the phenomena associated with the germination of the latter. Fig. 46 is that of a section of a young conidium obtained from a four-day culture, Fig. 47 that of a conidium fixed when about one month old. The first was fixed in Hermann's solution, the second by immersion in Flemming's stronger solution for one hour. Observation of the living material had led me to expect differences in the number of the nuclei. There were, however, no differences of importance observable. The difference in the number of nuclei observed in the sections comes well within the limit of variation. One could in fact obtain scores of sections in one slide with the numbers in the opposite proportion. The older conidia are generally vacuolated, and the unequal distribution of the vacuoles leads to an unequal 


\section{Trow.-Observations on the Biology and}

distribution of the nuclei. The section adjacent to that represented in Fig. 47 was conspicuous for its vacuoles and the small number of nuclei. The following countings may be of interest. One section of a conidium $12 \mu$ in diameter had three nuclei, five sections each $14 \mu$ in diameter showed respectively $8,7,8,6$, and 5 nuclei, and four sections each I $6 \mu$ in diameter showed respectively 10, 6, 6, and II.

Figs. 48 and 49 are drawn from material preserved in chromacetic acid. Fresh conidia were placed in cabbagesolution for about an hour and then fixed. The nuclei are very distinct, but the finer details are not so sharp as in material fixed with Flemming's or Hermann's solutions. The beautiful reticulate structure of the cytoplasm is likewise absent. The plane of section in the case shown in Fig. 49 was parallel to the direction of one of the germ-tubes. One spindle is seen in these figures quite comparable to those present at other stages, and three cases of 'double' nuclei. One is obviously justified in describing the first stage in the germination of the oospores as the conversion of the oospore into a conidium. One can easily understand, now that the cytological details are known, the peculiar behaviour of the oospores in germination. There appears to be no necessity for tracing the development of the germ-tube in the germinating oospore, for the behaviour must correspond exactly to that described and figured in the case of the conidia. The structure of the hyphae has been frequently observed, and corresponds to that shown in the germ-tube of Fig. 49. We have then before us a clear picture of the cytological details at all stages of the life history. Certain gaps in our knowledge, indeed, remain to be filled up, but these are of minor importance.

It may be of advantage to bring together the observations made on the structure of the nucleus. The resting nucleus is vesicular with a distinct nuclear membrane. In the centre is a chromatic mass, and traversing the 'nuclear sap' between this and the nuclear membrane is a very delicate network of 'linin' threads with very little chromatin attached to them. 
When karyokinesis begins the chromatic mass gradually breaks up, the chromatin passes out on to the linin threads, and a distinct nucleolus remains behind. As the spirem stage is reached, the network of linin bearing the chromatin granules becomes very evident. The nucleolus sometimes persists until the spindle has been fully formed, and even until the metaphase condition is reached. The nuclear membrane can be recognized until the nucleus is in metaphase, but at later stages it is not possible to trace it definitely. The achromatic figure appears to arise entirely within the nucleus, and of its threads those which serve to connect the daughter-chromosomes can be readily recognized in the last stages of division. The number of chromosomes is certainly as many as six, probably more. It is difficult to get definite results on this point. If the stain is too deep there is a danger of counting two adjacent chromosomes as one; if not deep enough the chromosomes are apt to be overlooked. The chromosomes are, in fact, so small that deep differential staining and the best objectives are necessary for their proper resolution. The nuclei, at all stages in the life history, agree in general appearance when seen in division, the impression being created that there is no variation in the number of the chromosomes.

\section{OBSERVATIONS OF TAXONOMIC INTEREST.}

At an early stage of the investigation it became apparent that the Fungus was either a species hitherto undescribed or described so inadequately as to be difficult of recognition. The knowledge which we have gained of its characters leaves no doubt as to the affinities of the species. It resembles Pythium vexans most closely, a species, as Fischer ('92) points out, incompletely investigated and inadequately described by De Bary ('81).

De Bary's figures of $P$. vexans, however, show conclusively that our species is a distinct one. In fact, if we are to unite it with $P$. vexans we must ascribe to De Bary a carelessness and want of insight altogether foreign to that brilliant and 
indefatigable botanist, to whose labours we owe so much of our knowledge of the Peronosporaceae.

As the species stands at the end of a series indicating greater and greater adaptation to a terrestrial existence, as evidenced by the fact that it alone has lost all power of producing zoospores, I propose for it the name Pythium ultimum. The specific name will thus serve to call attention to its position in the genus. The species may be defined as follows :-

\section{Pythium ultimum, n. sp.}

Mycelium saprophytic on boiled potatoes, house-flies, cabbage leaves, and other vegetable and animal substrata, never parasitic; either aërial and then very luxuriant, and snow-white like cotton 'wool' (as in potato cultures), or aquatic and inconspicuous; extramatrical and intramatrical; hyphae very long $(6 \mathrm{~cm}$.) and slender, the diameter varying from $6.5 \mu$ to I.7 $\mu$ (average of sixteen measurements $=3.8 \mu$ ), much branched, septate in old cultures, the septa separating the older empty parts of the hyphae from the younger.

Conidia chiefly terminal and spherical, with a diameter varying from $28 \mu$ and more to $I 2 \mu$ and less (average of 25 measurements $=20 \mu$ ), but occasionally intercalary and barrelshaped, with the dimensions varying from $27.8 \mu \times 22.9 \mu$ to I $7 \mu \times I_{4} 4$; set free by the decay of the supporting hyphae and germinating at once in nutrient solutions (in an hour if placed in cabbage-water) with the formation of one or more germ-tubes; remaining at rest in exhausted nutrient solutions or distilled water for so long a period as seven months without loss of germinating power, and showing no tendency to form zoospores either in distilled water or running tap-water; multinucleate.

Oogonia, terminal and spherical, very rarely intercalary, with a diameter ranging from $22.9 \mu$ to $19.6 \mu$ (average of 14 measurements $=20.6 \mu)$; smooth.

Antheridia, generally one to each oogonium, arising from the stalk of the oogonium immediately below its boundary 
wall, curved; sometimes especially in luxuriant cultures, two to an oogonium, and then often of diclinous origin and frequently straight.

Oospores, one in each oogonium, spherical, the diameter varying between $\mathrm{I} 8.3 \mu$ and $14.7 \mu$ (average of fourteen measurements $=I 6.3 \mu)$ with a smooth thick two-layered wall of yellowish colour, enclosing finely granular cytoplasm, a central reserve globule and one lateral nucleus; germinating at once or after a period of rest extending to seven months and always by one or more germ-tubes.

Zoospores are never developed.

Fischer ('92) in Rabenhorst's Kryptogamen Flora places Pythium in the Peronosporaceae. He further divides the Peronosporaceae into the Planoblastae and Siphoblastae. Of course the genus Pythium as originally defined was planoblastic, but, as we have seen, Pythium ultimum, while agreeing with its fellows in other respects, is siphoblastic. This subdivision of the Peronosporaceae is not based on a sound principle, for even if we regard Pythium ultimum as an exception, similar remarks apply to the old genus, Peronospora. The subdivision proposed involves the separation of like from like.

Schröter ('93) in the Pflanzenfamilien places Pythium in a special group-the Pythiaceae-and this has much to recommend it, as Pythium differs very considerably from the other members of the Peronosporaceae. The Pythiaceae are, however, separated from the Peronosporaceae, and included with the Saprolegniaceae in a group, the Saprolegniineae. Schröter was probably greatly impressed with the similarity in the 'habit' and the 'mode of life' of certain species of Pythium and many members of the Saprolegniaceae. It must be remembered, however, that none of the Saprolegniaceae produces a periplasm, and this difference in character in itself is quite sufficient to justify us in preferring Fischer's classification. It may be added that I have found the cell-wall in Saprolegniaceae to consist invariably of typical cellulose. In Pythium 
ultimum the cell-wall does not readily give the cellulose reaction with iodine and sulphuric acid. The reason for the difference has still to be accurately determined. The sum of the characters in Pythium, which is of course the best test of affinity, compels us to assign it a place in the Peronosporaceae. In this group it occupies, as is generally admitted, the lowest place. The adherence to the aquatic habit, the frequency of the saprophytic mode of life, the rudimentary type of oospore wall, and the crude nature of its attack on its hostif parasitic, destroying rather than enslaving-serve to distinguish it sharply from the more highly placed genera such as Peronospora and Cystopus. It would be interesting to have a more detailed knowledge of Phytophthora. In the present state of our knowledge it seems to be more closely related to Pythium than to the other two genera, and to occupy roughly an intermediate position.

\section{General Considerations.}

It had been hoped that incidentally this research would have thrown some light on that difficult and engrossing problem the alternation of generations in plants. I ('99) have already indicated in the Annals of Botany how a study of the cytology of the Thallophytes may be expected to throw light on this question. It may be well to call to mind that plants are known to possess two kinds of gametes, those as in Fucus, where the nuclei possess half the usual number of chromosomes; and those, as in Lilium, where the nuclei possess the full number. When the reduction in the number of chromosomes takes place in oogenesis and spermatogenesis, there cannot well be an antithetic alternation of generations. However great the diversity in the different generations due to special adaptation to the environment, we never get further than polymorphism of the gametophyte. When antithetic alternation typically occurs the reduction is known to take place during the development of the spores. The fact that plants certainly present these two definite cases is not even yet properly appreciated. 
To which of these two cases does our plant belong? If a second division occurs in the gametangia, accompanied by a reduction in the number of chromosomes, then it obviously belongs to the first. If no second division takes place, it does not necessarily belong to the second. There may be a third type, with the features of which we are not yet acquainted. It would have, of necessity, to go into the second group only if it could be shown that a process of reduction in the number of chromosomes takes place in the germinating or resting zygote, similar to that which is supposed to take place in the embryosac mother-cell of Lilium.

We can, unfortunately, come to no definite conclusion from the facts hitherto disclosed in this species. The probabilities are that the gametes have nuclei with the same number of chromosomes as those of the vegetative nuclei. We are thus brought face to face with the fact that an apparently unnecessary nuclear division takes place. What is the significance of this division? The view advanced first by Hartog in a similar case and provisionally adopted by others, that it is an ancestral character with no present physiological significance, does not appeal to me if only for the reason that it tends to check further investigation. Moreover, its general occurrence in coenocytic plants of widely different character, such as Cystopus Bliti, Peronospora, Saprolegnia, Achlya, and Pythium, suggests that its present importance is by no means inconsiderable. The case of Pythium suggests the validity of the explanation which has already been advanced by Strasburger ('97), that these divisions are essential stages in the differentiation of gametes. As a general view the theory, however, does not appear to be admissible, for, according to Lagerheim ('00) and Oltmanns ('95) there do not appear to be any preliminary divisions in Monoblepharis and Vaucheria. In the Peronosporaceae and Saprolegniaceae the case is different. In Pythium in particular the unpractised eye cannot distinguish a conidium from a young oogonium. It is demonstrable too, in sections, that by the time the young antheridium makes its appearance the oogonial nuclei are preparing to divide. 


\section{Trow.-Observations on the Biology and}

Provisionally, at any rate, Strasburger's view may be adopted, and efforts should be made to extend our knowledge of the cytology of the gametangia and gametes in the sexual Thallophytes. It is probable that gameto-nuclei are much more susceptible to degenerative changes than vegetative nuclei. If so, the advantage of all the nuclei retaining their powers of division, rather than one only, is clear. The daughter-nuclei are more readily digested and absorbed.

Three types of fertilization have been described as occurring in the Peronosporaceae, but now that Fisch's type (Pythium) falls to the ground, there remain but two-the normal one common to most plants, and that described so fully by Stevens for Cystopus Bliti and styled concisely by Wager ('00), ' multiple nuclear fusions in pairs.'

Davis has endeavoured to harmonize these widely divergent types by deriving the Oomycetes from Zygomycete-like ancestors. It is perfectly easy to construct a subjective phylogeny in this way. Ideas of this kind are, however, of value chiefly in proportion to the amount of objectivity which they represent. It is just as easy to construct a phylogeny without reference to the Zygomycetes, which, though to a great extent theoretical, has a considerable foundation of fact.

We have in Monoblepharis a Fungus in which all the reproductive organs are still so much alike (sporangium-like) that their homology is at once apparent. Had the oogonium a number of oospores like that of Sphaeroplea, the resemblances would be more striking still. Saprolegnia offers little advance on the condition seen in Monoblepharis. The oogonia and sporangia are very similar. The numerous oospheres differ from the spores in size, owing no doubt to the fact that in their formation nuclei have been absorbed and digested. The successful nuclei preside over an unusual amount of cytoplasm. The antheridia are however reduced. The fewer the eggs, the smaller should the antheridia be. The reduction of the antheridium obviously goes hand in hand with the increase in size and diminution in number of the oospheres. Zooidiogamy 
has moreover been replaced by siphonogamy, rendering a further reduction possible. The siphonogamous type of fertilization is an advantageous because an economical one, even in the case of aquatic plants. It is interesting to note that Saprolegnia is nevertheless not quite perfectly adapted to its environment, as it still wastes a considerable number of male nuclei. The homologies in Saprolegnia are sufficiently clear.

How are we to understand the-case of Cystopus Bliti? Have we any facts to help us, or are we entirely dependent upon our imaginative powers? The homologies seem clear enough until we take account of the karyology. Let us remember what happens so frequently in the case of the sporangia of Pythium and Peronospora-genera closely allied to Cystopus. In these two genera, the sporangia, adapting themselves to new environments, are converted into 'conidia.' In some species the conversion is complete, in others, still in progress. Its characteristic feature is that one large coenocytic multinucleate conidium is developed in place of a sporangium, with an output of a number of small uninucleate zoospores. Does not the oogonium of Cystopus Bliti and other Peronosporaceae present to us the corresponding metamorphosis in the female gametangium? I think it does, and we are thus able by extending the view to the antheridia of the Saprolegniaceae and Peronosporaceae to get a clear, if novel, picture of the real condition of affairs in these curious plants. The fertilization-tube growing out from an antheridium towards the egg behaves exactly like the germtube of a conidium growing towards the leg of a fly. There are still difficulties, however, which need further explanation. It is especially necessary to seek some clue to the origin and significance of the periplasm. We can easily imagine how, owing to inequalities in the numbers of female and male nuclei, the excess of female nuclei were pressed out to the periphery. Or it may have been the amount of protoplasm requisitioned by each nucleus that led to this resultone exemplified by the Fucaceae at the present day. One can further imagine undesirable 'energids' being pressed out 
altogether and not simply their nuclei. In this way the periplasm probably arose. There is nothing very remarkable in the fact that the male and female nuclei in Cystopus Bliti fuse in pairs, for this propensity they have no doubt inherited from their algal ancestors. We have now only to go a step further and imagine the habit of the nuclei of monopolizing the cytoplasm of their neighbours (as already seen in Saprolegnia), still further intensified to see how the uninucleate egg might arise in such forms as Cystopus candidus, Peronospora parasitica, and Pythium ultimum. There are many missing links in this chain of evidence no doubt, but perhaps one gap may be filled up by considering the behaviour of the nuclei in the differentiation of the oosphere in Pythium ultimum. More than one nucleus frequently remains behind in the egg to undergo division there. There is in this, at any rate, a suggestion of an ancestral condition in which numerous nuclei were present in the oosphere.

It is now apparent that the uninucleate egg of Pythium ultimum and its allies, is the homologue of the multinucleate one of Cystopus Bliti-in the terminology of Stevens is a 'compound oosphere.' In view of this relation it is almost necessary for Stevens to withdraw or amend his terminology. It certainly seems rather absurd to describe the uninucleate oosphere of Pythium as compound.

It is obvious that the uninucleated egg might have been evolved in other ways, but this view gives us a provisional explanation of the periplasm which is not wholly theoretical, whilst limiting our speculations to the Oomycetes themselves. The cytology of the Zygomycetes is so obscure at present, as Davis has well said; and the forms mentioned by him, in his attempt to create a phylogeny for Cystopus Bliti, show such remote affinity to the Peronosporaceae, that $I$ feel it would be a mistake at present to direct attention to the Zygomycetes with a view to harmonizing these two types of fertilization. There certainly appears, contrary to the view propounded by Davis, to be no difficulty in connecting Cystopus Bliti, through forms like Cystopus candidus, Pythium, 


\section{Cytology of Pythium ultimum, n. sp.}

Saprolegnia, and Monoblepharis, with algal ancestors of the type of Sphaeroplea, Vaucheria, or Oedogonium.

It may not be superfluous to add that whatever view may be taken of fertilization-whether it is regarded as a means of rejuvenescence or as the source of an indefinite number of fortuitous variations-the two types present in the Peronosporaceae are of almost equal efficiency.

It is noteworthy that Harper ('00) has just published an account of the fertilization-processes in Pyronema which serves to confirm to a considerable extent the hitherto unique observations of Stevens, and even perhaps to strengthen De Bary's view of the affinity between the Ascomycetes and Peronosporaceae.

Harper ('00, p. $3^{80}$ ), however, does not appear to have grasped the significance of the facts published by Stevens, for he points out that the multinucleate conidia of Cystopus are not called 'compound,' although from analogy with the multinucleate oosphere that might have been expected. There is a very curious confusion of ideas here, from which Stevens himself is not exempt, if it be true, as Harper states, that he makes use of the term 'compound antheridium.' I have not been able, however, to trace this term to Stevens. The homologues of the oospheres are the sperms and zoospores, not the antheridia and sporangia. The conidia of Cystopus are sporangia, having indeed a considerable output of zoospores. The sporangium in this case has retained its characteristic power of producing zoospores, but acquired in addition a special capacity for dissemination. The antheridium and oogonium have, however, developed along different lines. The sperms which pass into the oosphere of Cystopus Bliti might collectively be called the compound sperm, just as the more definitely differentiated oosphere is called the 'compound oosphere.' To put the matter more plainly still, if De Bary's view of a gonoplasm could be shown to be true, and the gonoplasm were multinucleate, the gonoplasm would be a compound sperm. Similarly the conidium of Pythium is, phylogenetically considered, a compound spore. Stevens' 


\section{Trow.-Observations on the Biology and}

terminology, even if an unsuitable one, may serve a good purpose if it aids us in rearranging our ideas concerning fertilization. No clear idea of this complicated question, though, will be gained while gametangia are confused with gametes and sporangia with spores.

\section{SUMMARY.}

The conidia of this Fungus were found in rotten cressseedlings in July, I899, and the species has been cultivated as a saprophyte on sterilized potatoes, house-flies and cabbage leaves, \&c., up to the present time (January, 190I).

The species appears to be a pure saprophyte, all attempts to infect fresh cress-seedlings having failed.

Pure cultures were obtained by infecting sterilized potatoes with material obtained from fairly pure cultures on rhubarb leaves.

On potatoes, an aërial mycelium is freely developed, which remains sterile for weeks. If the culture is prevented from drying up, crops of conidia and oospores are ultimately obtained.

An aquatic mycelium is produced in cultures grown on house-flies and bits of cabbage leaves immersed in water. The reproductive organs make their appearance when the culture is two or three days old, and as a rule the house-fly cultures produce conidia, and the cabbage-leaf cultures oospores only.

The whole life-history has been carefully followed in moistchamber cultures. The chief features, as determined by De Bary and others for the genus, have been verified; but in addition it is clear $(a)$ that De Bary erred in including the greater part of the periplasm in the oosphere, and in describing a sharp differentiation of periplasm and gonoplasm in the antheridium; and $(b)$ that the periplasm is digested and absorbed by the young oospore, which, in consequence, increases in size.

The conidia and oospores invariably produce germ-tubes 
on germination. No zoospores have been observed. The species is consequently new, and ranks as the most highly developed of the genus. The generally accepted definition and affinities of the genus require considerable modification.

The conidia germinate at once in cabbage-water, but remain at rest in distilled water. The behaviour of the oospores remains to be further investigated, but it is certain that they will germinate as soon as ripe, or after a rest of seven months.

The mycelium, conidia, oogonia, and antheridia are multinucleate, the oosphere and the ripe oospore uninucleate, and the young oospore binucleate.

The nuclei multiply in the mycelium and sexual organs by indirect division. No nuclear divisions have been seen in the conidia except during germination. No nuclear fusions take place other than those of the male and female nuclei in fertilization. The number of chromosomes is considerable, certainly six or more.

The oogonium, as it is formed, receives twelve or more nuclei, the antheridium three or more. These invariably divide once, so that the number of nuclei, although already greatly in excess of the requirements of the organs, is doubled. The supernumerary nuclei in the oogonium pass into the periplasm, one only remains behind and occupies the centre of the egg. No similar differentiation takes place in the antheridium.

The fertilization-tube penetrates the wall of the oogonium, passes through the periplasm, and penetrates deeply into the egg. One male nucleus passes down the tube and enters the egg. The oosphere clothes itself with a delicate cell-wall and proceeds to digest and absorb the periplasm, increasing in size during the process.

The male and female nuclei do not fuse until a thick oospore-wall has been produced. As the oospore ripens a reserve globule is formed in the centre of the oospore and the fusion-nucleus is forced to one side. No epispore is developed. 


\title{
3 IO Trow.-Observations on the Biology and
}

In the germination of the oospore, the reserve globule (probably consisting of proteids and fats or oils) and the inner wall of the spore are decomposed and absorbed, the nucleus undergoes division, and a conidium-like condition is acquired.

\author{
University College, Cardiff, \\ January, I90I.
}

\section{LITERATURE.}

The following list includes the most important papers relating to the subject of this communication which have appeared in recent years. Very complete bibliographies of the older literature will be found in many of them.

BerLese, A. N., '97 : Ueber die Befruchtung und Entwickelung der Oosphäre bei den Peronosporeen. Jahrb. f. wiss. Botanik, Bd. xxxi, Heft 2.

DANGeard, P. A., '90: Recherches histologiques sur les champignons. Le Botaniste, $2^{\circ}$ sér., $2^{\circ}$ fasc.

'92: Recherches sur la reproduction sexuelle des champignons. Le Botaniste, $3^{\ominus}$ sér., p. 229.

Davis, Bradley Moore, '00: The fertilization of Albugo candida. Bot. Gaz., vol. xxix, p. 297 .

De BARy, '81: Zur Kenntniss der Peronosporeen. Bot. Zeit., Jahrgang 39, No. 34 .

'87 : Comparative Morphology and Biology of the Fungi, \&c. Oxford, 1887.

Fisch, C., '85 : Ueber das Verhalten der Zellkerne in fusionirenden Pilzzellen. Bot. Cent., Bd. xxiv, p. 22 I.

Fischer, Alfred, '92 : Phycomycetes. Rabenhorst's Krypt.-Flora von Deutschland, 2. Aufl., Bd. i, Abt. iv.

- Goebel, K., '00 : Organography of Plants, Part I, Oxford, I900.

Harper, Robert A., '00: Sexual Reproduction in Pyronema confuens and the Morphology of the Ascocarp. Annals of Botany, vol. xiv, No. 55.

HartoG, M. M., '95: On the Cytology of the Vegetative and Reproductive Organs of the Saprolegnieae. Trans. Roy. Irish Acad., vol. xxx, Part I 7 .

Humphrey, J. E., '92: The Saprolegniaceae of the United States. Read before the American Philosophical Society, Nov., I892.

IstvanfFI, Gy. von, '95 : Ueber die Rolle der Zellkerne bei der Entwickelung der Pilze. Ber. der Deutsch. Bot. Ges., Bd. xiii, p. $45^{2}$.

KLEBS, G., '96 : Die Bedingungen der Fortpflanzung bei einigen Algen und Pilzen. Jena, 1896. 
KLebs, G. '98: Zur Physiologie der Fortpflanzung einiger Pilze. I. Sporodinia grandis. Jahrb. für wiss. Bot., Bd. xxxii.

'99 : Zur Physiologie der Fortpflanzung einiger Pilze. II. Saprolegnia mixta. Jahrb. für wiss. Bot., Bd. xxxiii, Heft 4.

'00: Zur Physiologie der Fortpflanzung einiger Pilze. III. Allgemeine Betrachtungen. Jahrb. für wiss. Bot., Bd. xxxv, Heft I.

LAgerheim, G., '00: Mykologische Studien. II. Untersuchungen über die Monoblepharideen. Meddelanden fran Stockholms Högskola, No. I99. Bihang till K. Svenska Vet.-Akad. Handlingar, Bd. xxv, Afd. III, No. 8.

Ortmanns, F., '95: Ueber die Entwickelung der Sexualorgane bei Vaucheria. Flora, Bd. 1xxx, Heft 2, p. 388 .

Schröter, J., '93 : Die natürlichen Pflanzenfamilien. Engler-Prantl. I. Teil, I. Abtheilung.

Stevens, F. L., '99: The compound oosphere of Albugo Bliti. Bot. Gaz., vol. xxviii, p. I 49 .

Strasburger, E., '97 : Cytologische Studien. Berlin, I 897 .

Swingle, Walter T.,'98: Two new organs of the Plant-cell. Bot. Gaz., vol. xxv, No. 2 , p. I IO.

Trow, A. H., '95 : The Karyology of Saprolegnia. Annals of Botany, vol. ix, No. 36 .

'99: Observations on the Biology and Cytology of a new variety of Achlya americana. Annals of Botany, vol. xiii, No. 49, p. I3I.

Von Tavel, F., '92 : Vergleichende Morphologie der Pilze. Jena, I892.

WAger, H. W. T., '89: Observations on the structure of the nuclei in Peronospora parasitica. Annals of Botany, vol. iv, No. xiii, p. I27.

'96: On the structure and reproduction of Cystopus candidus, Lév. Annals of Botany, vol. x, p. 295 .

'00: On the Fertilization of Peronospora parasitica. Annals of Botany, vol. xiv, p. 263.

Ward, H. Marshall, '83: Observations on the genus Pythium (Pringsh.). Q. J. M. S., New Series 23, Series 3, vol. i, Part 2. 


\section{I 2 Trow.-Observations on Pythium ultimum, n. sp.}

\section{EXPLANATION OF THE FIGURES IN PLATES $\mathrm{XV}$ AND XVI.}

Illustrating Dr. Trow's paper on Pythium ultimum, n. sp.

All the figures were drawn with the help of the camera lucida. Figs. I-5 are representations of living material, the remaining ones are drawings of stained sections. Those of the first set are magnified about $55^{\circ}$, of the second about $125^{\circ}$ diameters. All the sections were $5 \mu$ thick. Median sections, i. e. the middle ones of series, are shown with one exception, viz. Fig. I6.

Fig. I. Structure and germination of an intercalary conidium.

Fig. 2. Structure and germination of a terminal conidium.

Fig. 3. Stages in the development of an oogonium and antheridium.

Fig. 4. Further stages in the development of an oogonium and antheridium. Fertilization.

Fig. 5. Stages in the maturation of an oospore.

Figs. 6-32. Approximately successive stages in the development of the gametangia, in fertilization, and in the maturation of the oospores. Full description in the text.

Figs. 33-40. Successive stages in the germination of the oospores, the fate of the reserve globule being neglected. The wall of the oogonium is represented in Figs. $38-40$.

Figs. $4^{\mathrm{I}-45}$. Successive stages in the germination of the oospores, the fate of the reserve globule being followed. The wall of the oogonium is represented in Fig. 43-45.

Fig. 46. Young conidium fixed in Hermann's solution.

Fig. 47. Month-old conidium fixed by immersion in Flemming's stronger solution for one hour, too short a time to secure good results.

Figs. 48 and 49. Conidia fixed in chromacetic acid while germinating. Chromic acid $\cdot \%$, Acetic acid $\cdot 3 \%$. 


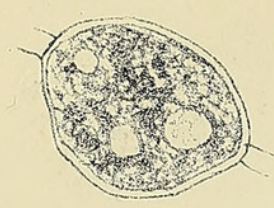

$1^{\mathrm{a}}$. $9.58 . \mathrm{a.m}$

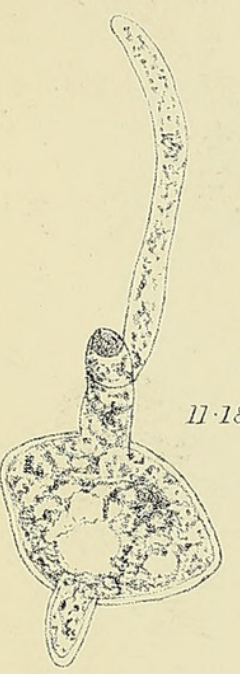

$1^{f}$.

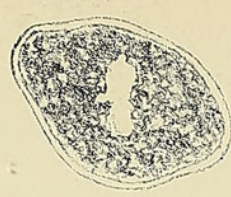

$1^{b} \cdot \quad 10 \cdot 40.0 . m$

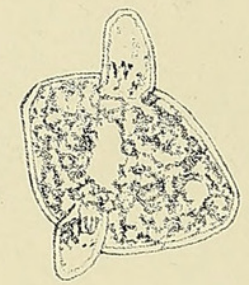

1 .

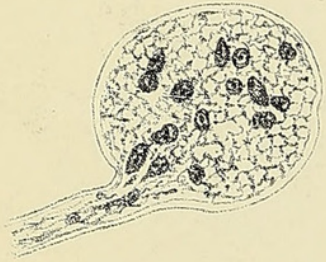

6.

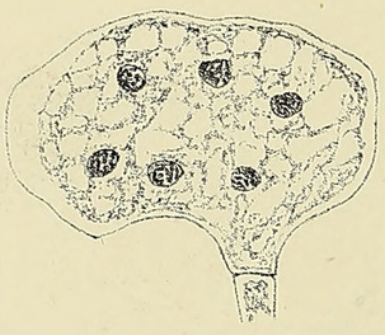

7.

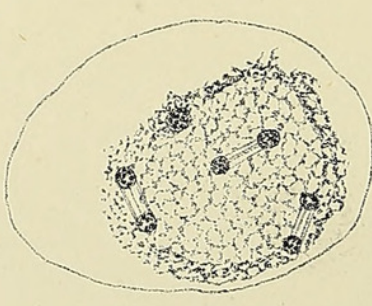

10.

9.

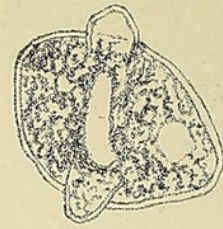

$$
\begin{array}{ll}
\text { 1. } 20.48 .0 . m . & 1^{d} . \\
& 10.51 .0 . m
\end{array}
$$
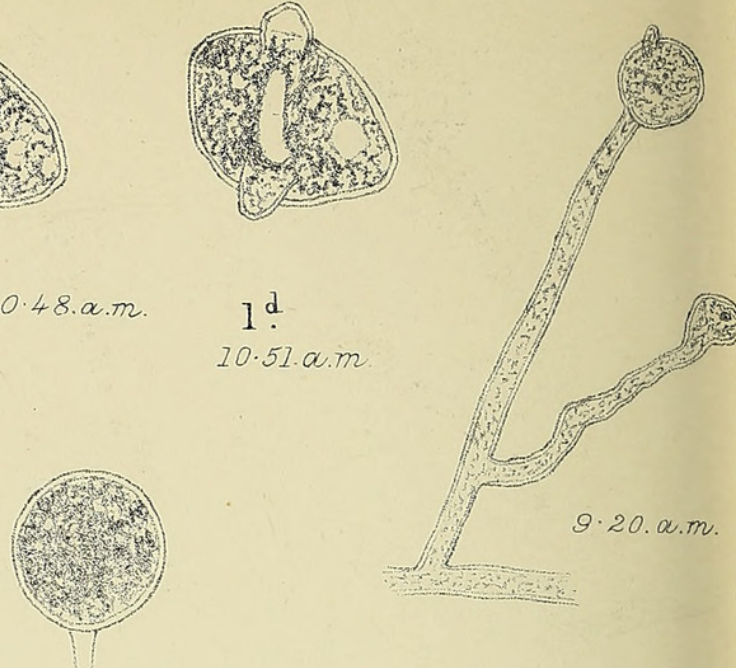

$3 a$

$10.0 \mathrm{a.m}$

$2^{2}$

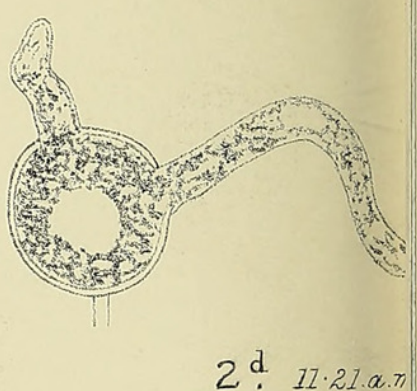
$2^{b} \cdot 72 \cdot 2 \cdot a \cdot m$
2 c $11 \cdot 10 \cdot a \cdot m$

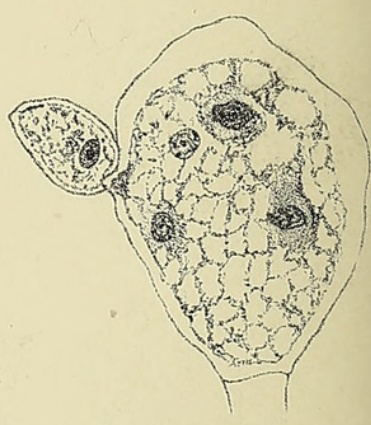

8.

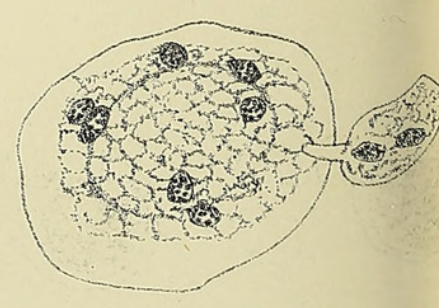

11.

A.H.Trow, del. 
Annals of Botany.

Vol XVPLXV.

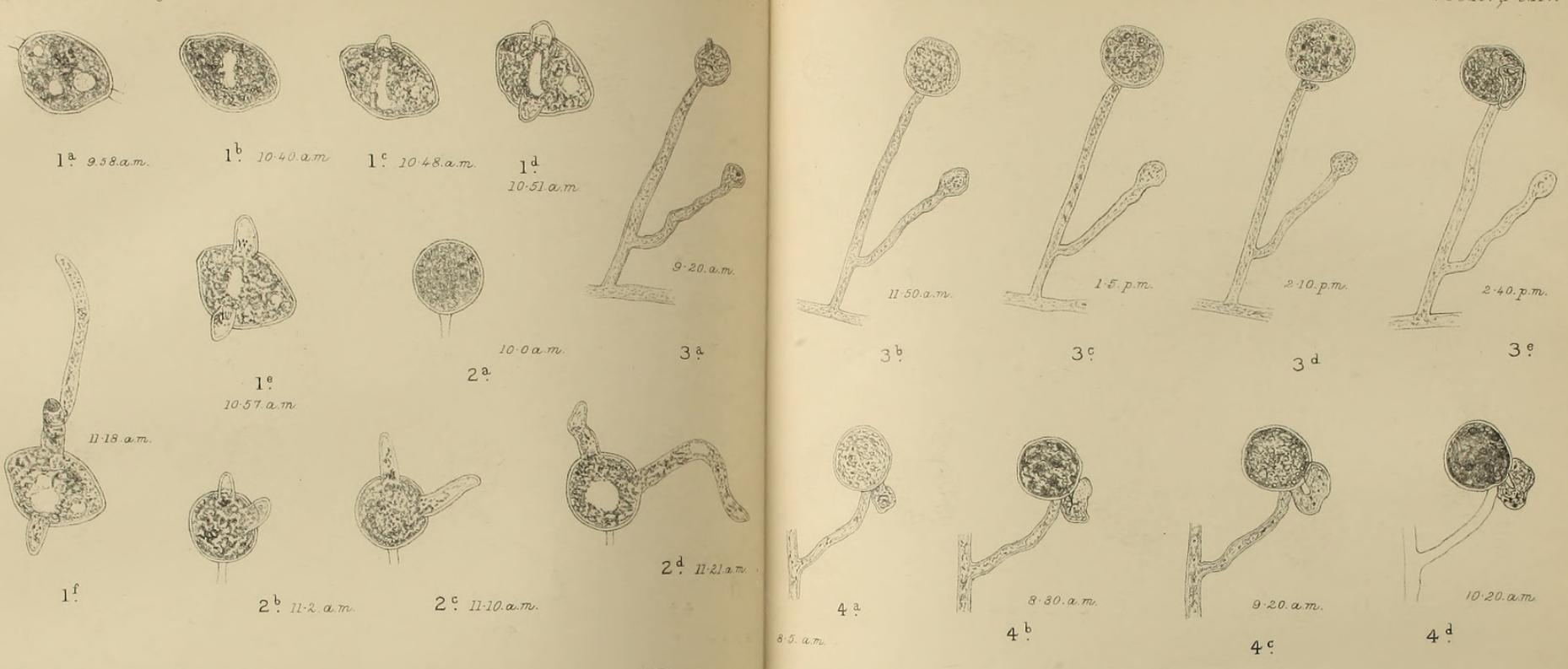

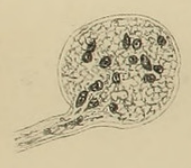

6.

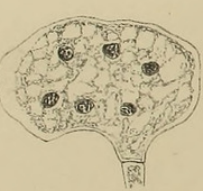

7.

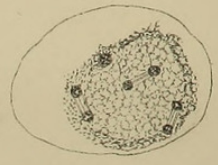

10.

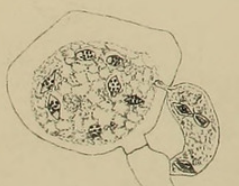

9.

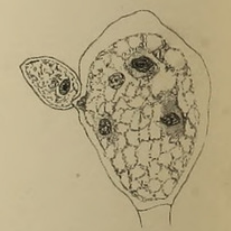

8.

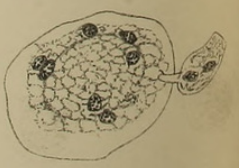

11.

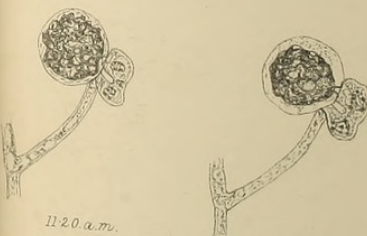

4 .

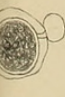

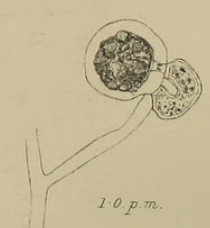

$4 \stackrel{\S}{.}$

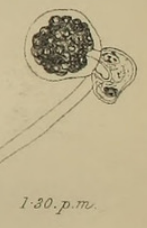

$4 \stackrel{h}{.}$

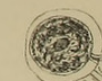

A.H.Trow, del.
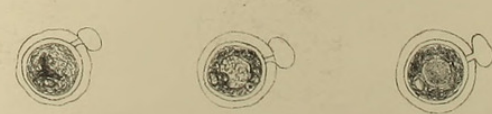

$5 ? .11 \cdot 0 \cdot a, 7 \pi$ 5 ?
$21 \cdot 0.2 . m$
$81 \cdot 8.99$

5: $n \cdot 0 . a \cdot m$

5 d. $31 \cdot 0.0 . m$ 


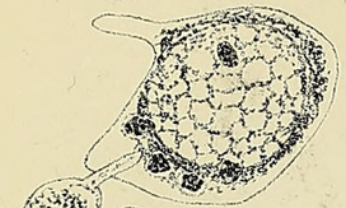

12.

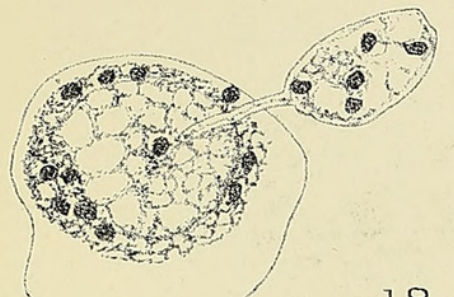

18.

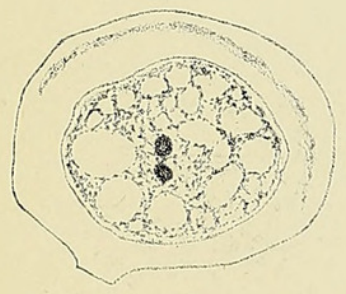

24

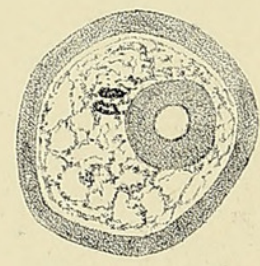

32.

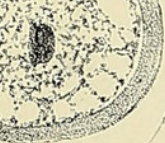

31.
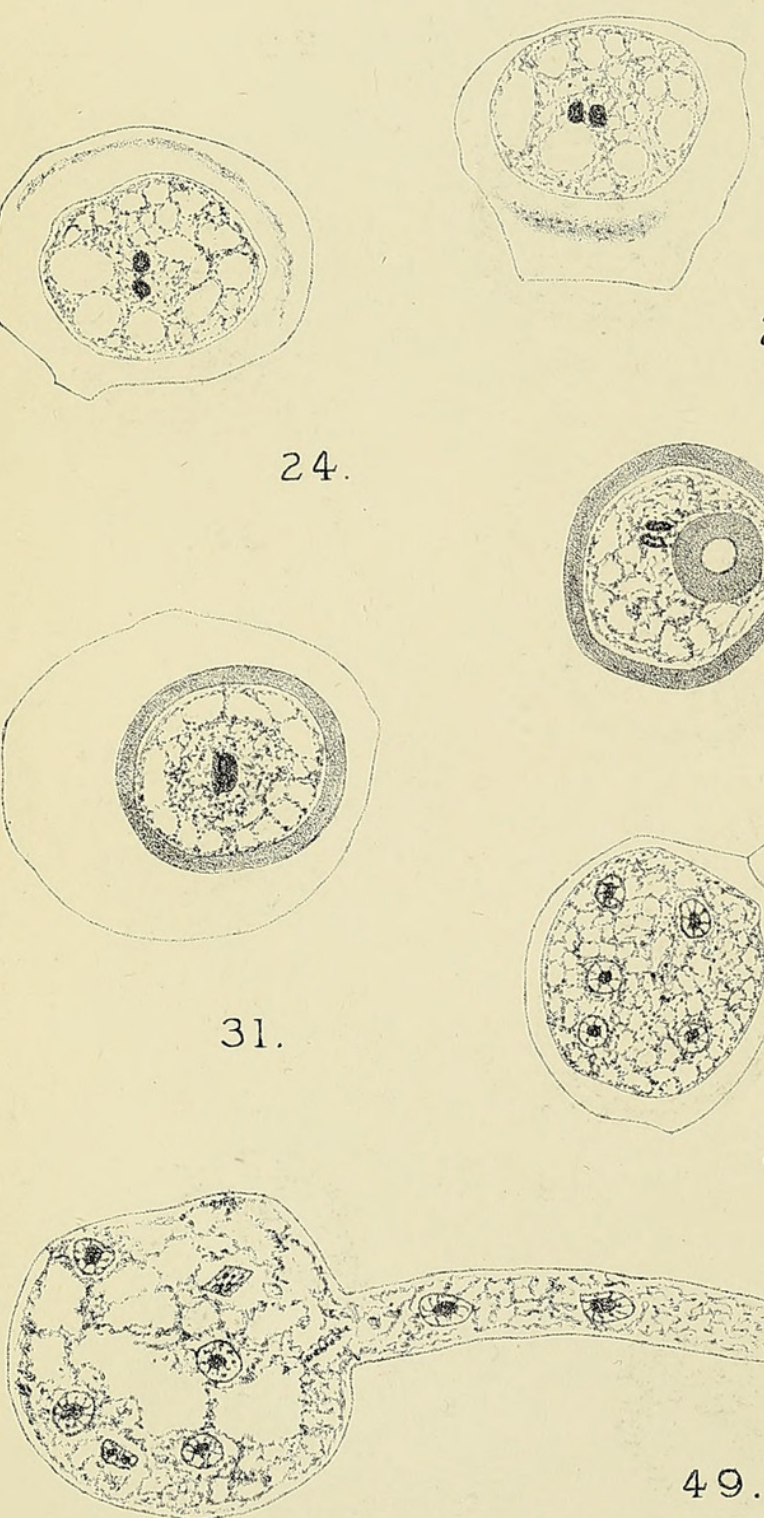

25

19.

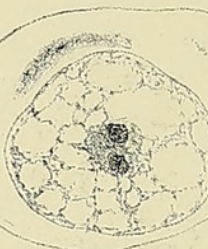

26

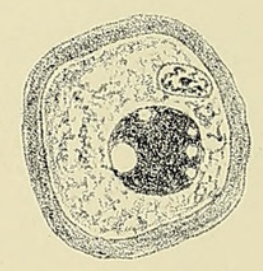

33.

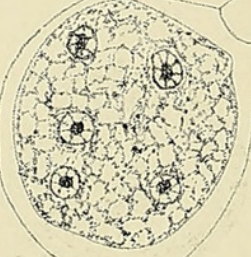

46.

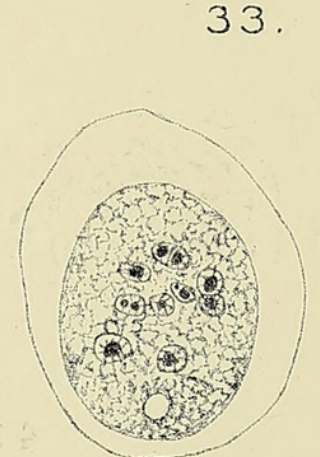

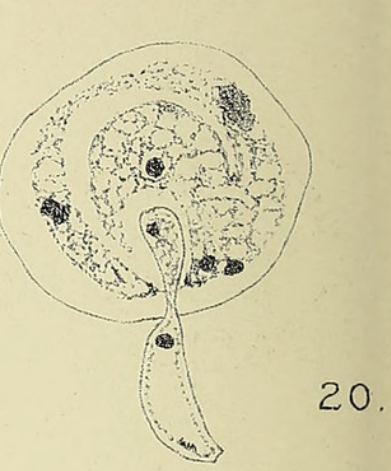

14.

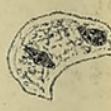

13.

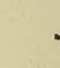



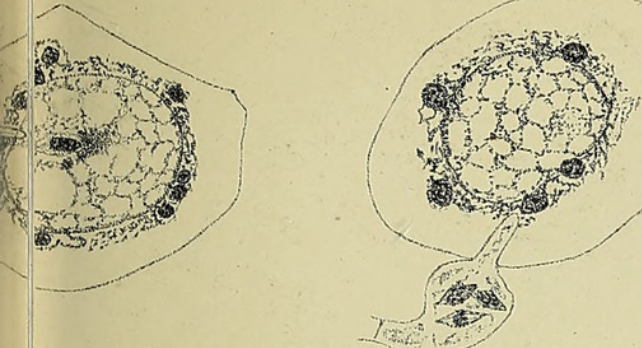

16 ?

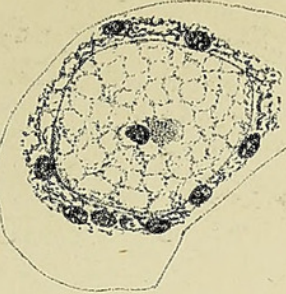

$16^{b}$

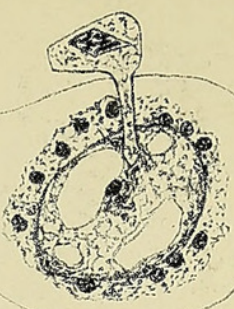

17.

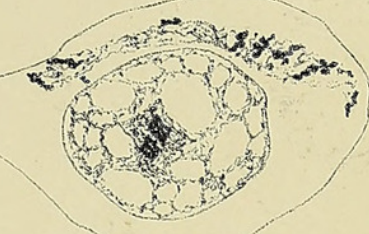

23.
21.

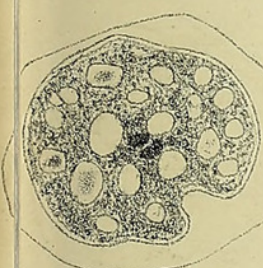

28
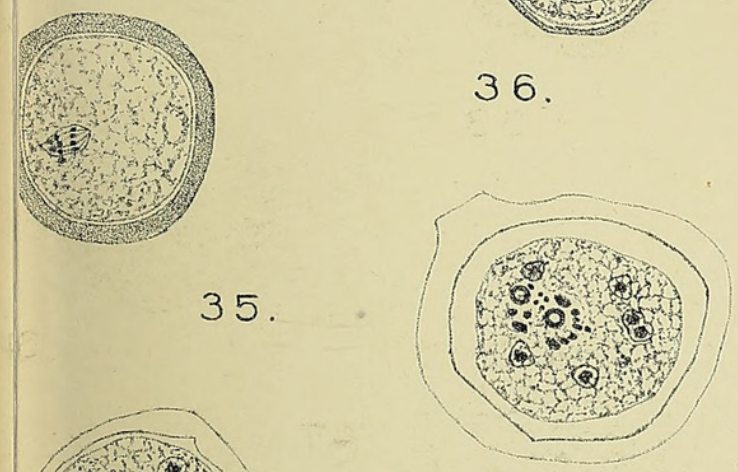

43.

45

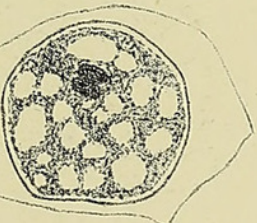

29.

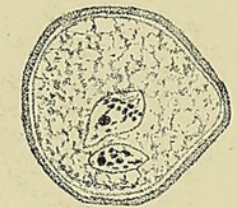

36

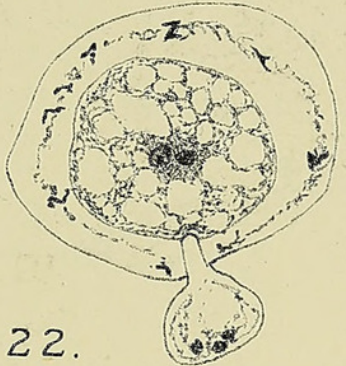

30.

37
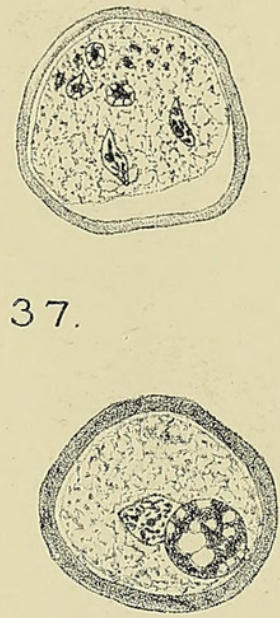

41 .

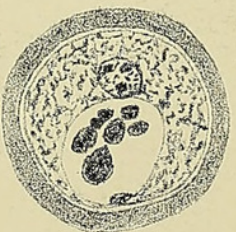

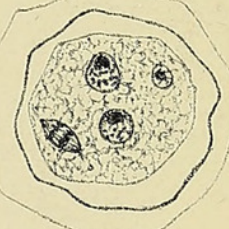

38.

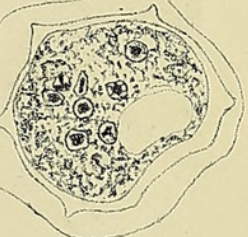

39.

42. 


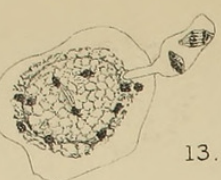

13

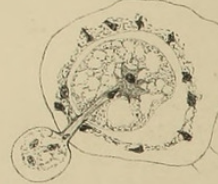

18.

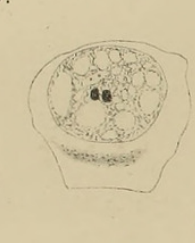

19

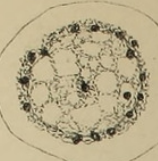

81

14.

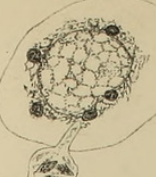

16 ?
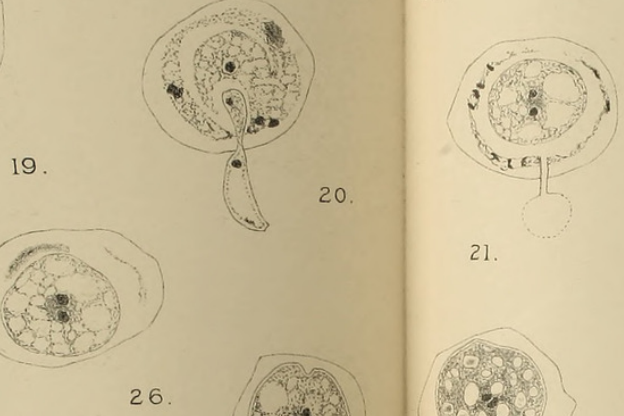

21

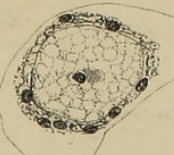

$16^{b}$
Vol.XV,Pl.XVI.

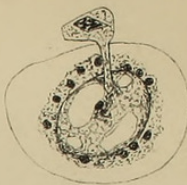

17.

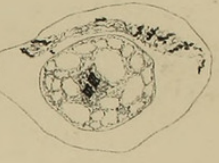

23

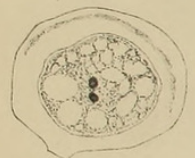

24
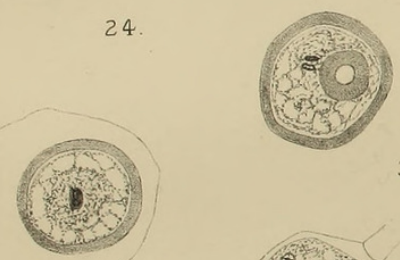

32.

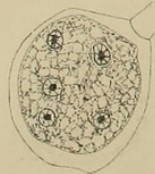

46
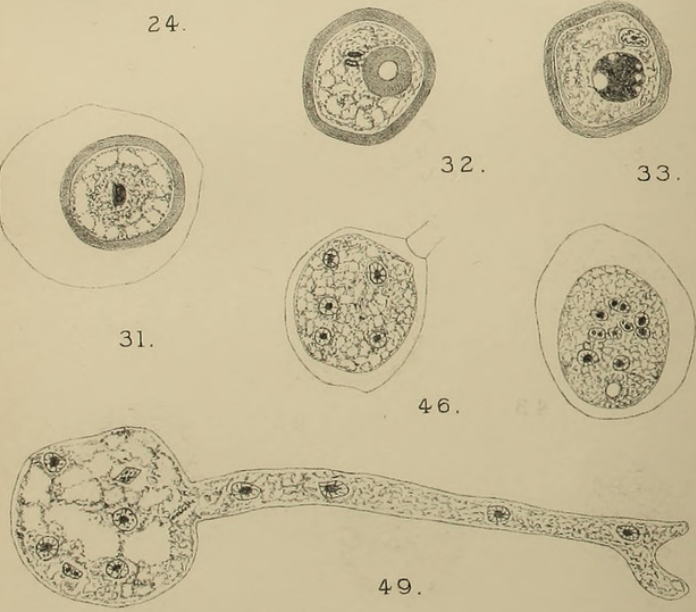

33

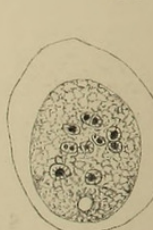

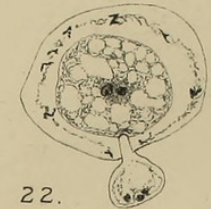

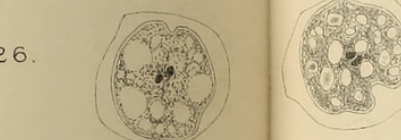

47.

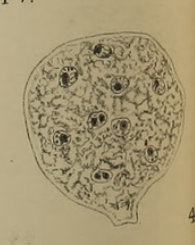

(1) 8 .

(6.) 0 ?

45 .

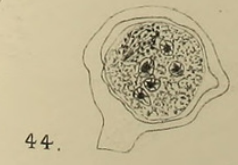

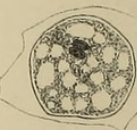

29.

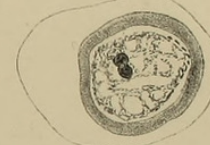

30.

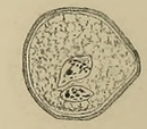

36.

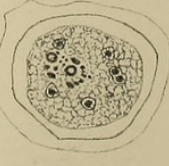

37.

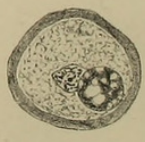

41.

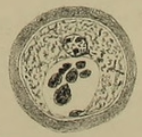




\section{$2 \mathrm{BHL}$ Biodiversity Heritage Library}

Trow, Albert Howard. 1901. "Observations on the biology and cytology of Pythium ultimum, n. sp." Annals of botany 15, 269-312.

https://doi.org/10.1093/oxfordjournals.aob.a088819.

View This Item Online: https://www.biodiversitylibrary.org/item/236929

DOI: https://doi.org/10.1093/oxfordjournals.aob.a088819

Permalink: https://www.biodiversitylibrary.org/partpdf/318623

\section{Holding Institution}

Smithsonian Libraries

\section{Sponsored by}

Biodiversity Heritage Library

\section{Copyright \& Reuse}

Copyright Status: Not in copyright. The BHL knows of no copyright restrictions on this item.

This document was created from content at the Biodiversity Heritage Library, the world's largest open access digital library for biodiversity literature and archives. Visit BHL at https://www.biodiversitylibrary.org. 